\title{
Luminescent Metal Nanoclusters for Potential Chemosensor Applications
}

\author{
Muthaiah Shellaiah ${ }^{1}$ and Kien Wen Sun ${ }^{1,2, *}$ \\ 1 Department of Applied Chemistry, National Chiao Tung University, Hsinchu 300, Taiwan; \\ muthaiah1981@nctu.edu.tw \\ 2 Department of Electronics Engineering, National Chiao Tung University, Hsinchu 300, Taiwan \\ * Correspondence: kwsun@mail.nctu.edu.tw
}

Received: 21 November 2017; Accepted: 8 December 2017; Published: 19 December 2017

\begin{abstract}
Studies of metal nanocluster (M-NCs)-based sensors for specific analyte detection have achieved significant progress in recent decades. Ultra-small-size $(<2 \mathrm{~nm}) \mathrm{M}-\mathrm{NC}$ s consist of several to a few hundred metal atoms and exhibit extraordinary physical and chemical properties. Similar to organic molecules, M-NCs display absorption and emission properties via electronic transitions between energy levels upon interaction with light. As such, researchers tend to apply M-NCs in diverse fields, such as in chemosensors, biological imaging, catalysis, and environmental and electronic devices. Chemo- and bio-sensory uses have been extensively explored with luminescent $\mathrm{NCs}$ of $\mathrm{Au}, \mathrm{Ag}, \mathrm{Cu}$, and $\mathrm{Pt}$ as potential sensory materials. Luminescent bi-metallic NCs, such as $\mathrm{Au}-\mathrm{Ag}, \mathrm{Au}-\mathrm{Cu}, \mathrm{Au}-\mathrm{Pd}$, and $\mathrm{Au}-\mathrm{Pt}$ have also been used as probes in chemosensory investigations. Both metallic and bi-metallic NCs have been utilized to detect various analytes, such as metal ions, anions, biomolecules, proteins, acidity or alkalinity of a solution $(\mathrm{pH})$, and nucleic acids, at diverse detection ranges and limits. In this review, we have summarized the chemosensory applications of luminescent M-NCs and bi-metallic NCs.
\end{abstract}

Keywords: nanoclusters; fluorescent assay; nanosensors; bio-imaging; real analysis; colorimetric recognition; biomolecules detection; bi-metallic clusters

\section{Introduction}

Metal nanoclusters (M-NCs) have attracted the attention of the modern scientific community, because of their cost effective synthesis, biocompatibility, photostability, and wide applications [1-5]. M-NCs consist of few atoms (mostly between ten to hundred) of comparable sizes similar to the Fermi wavelength of electrons [6-8]. Hence, M-NCs can be considered as the missing link between single metal atoms and plasmonic metal nanoparticles [9]. In contrast to plasmonic nanoparticles, M-NCs have a size less than $2 \mathrm{~nm}[10,11]$ and do not exhibit any plasmonic characteristics. In addition, upon interaction with light, M-NCs display absorption and emission properties via electronic transitions between energy levels as in the case of organic molecules [12]. Therefore, in recent times, researchers have tended to apply M-NCs in various studies such as chemosensors, biological imaging, catalysis, as well as environmental and electronic devices. Chemo- and bio-sensory applications of luminescent M-NCs have attained most impressive progress [13-15].

Luminescent $\mathrm{NCs}$ of $\mathrm{Au}, \mathrm{Ag}, \mathrm{Cu}$, and $\mathrm{Pt}$ have been successfully utilized as potential sensory materials [16-23]. Similar to organic fluorophores, carbon dots (CDs), and fluorescent quantum dots (QDs), luminescent M-NCs have been successfully applied in many sensor investigations because of their fluorescent nature, ultra-small size, and biocompatibility. Luminescent M-NCs have also been utilized in many in vivo/vitro biological imaging studies [24-27]. The stability of M-NCs has been improved using stabilizing agents. 
The presence of templates on the surface of M-NCs can improve the stability and enhance sensing ability by providing a binding unit on the surface. For example, template-protected Au NCs have been previously reported as extended analytical tools for species detection [28]. These templates/stabilizers can also improve the luminescent property and biocompatibility of the clusters. Similar to Au NCs, other metal NCs (Ag, Cu, and Pt NCs) have displayed comparable fluorescent properties in the presence of various stabilizers [29-31]. Therefore, M-NCs are formed by reducing metal ions in the presence of appropriate reducing agents. Thiols, dendrimers, polymers, DNA oligonucleotides, peptides, and proteins have been commonly used to stabilize or improve the opto-electric properties of M-NCs [32].

Scholars have reported various applications of luminescent bi-metallic NCs. Bi-metallic NCs can be developed through different synthetic techniques, such as (1) galvanic replacement reaction, (2) anti-galvanic replacement reaction, (3) potential deposition, (4) thiol-etching of bi-metallic nanoparticles, and (5) re-organization of bi-metallic species [33]. To date, $\mathrm{Au}-\mathrm{Ag}, \mathrm{Au}-\mathrm{Cu}, \mathrm{Au}-\mathrm{Pd}$, and Au-Pt NCs have been utilized in various fields, such as catalysis, sensors, and bio-imaging. Overall, chemosensor applications of both M-NCs and bi-metallic NCs have attracted interest because of their cost-effective operation in biological and environmental samples.

Both metallic and bi-metallic NCs have been effectively applied to detect various analytes, such as metal ions, anions, biomolecules, proteins, pHs, and nucleic acids. Furthermore, metallic and bi-metallic NCs have also been reported as suitable candidates for bio-imaging. In this review, we summarize the chemosensory applications of luminescent $\mathrm{M}-\mathrm{NCs}(\mathrm{M}=\mathrm{Au}, \mathrm{Ag}, \mathrm{Cu}, \mathrm{and} \mathrm{Pt})$, as presented in Figure 1. In addition, we provide a brief note on the sensory applications of other M-NCs (such as Cd, Al, Pd, and Ir NCs) and bi-metallic NCs.



Figure 1. Schematic representation of chemosensor applications of metal nanoclusters (M-NCs).

\section{Optimization Requirements}

The sensory and bio-imaging applications of M-NCs are dependent on the following requirements, which must be optimized before designing such probes.

A. Ligands: Suitable ligands must be selected to achieve enhanced fluorescence and tunable emissive colors, such as blue, green, red, orange, and yellow. Thiols, dendrimers, polymers, DNA-oligonucleotides, peptides, and proteins have been commonly used as ligands. Among them, ligands consisting of thiol groups have displayed outstanding results [34]. For example, Huang and Goswami's reports [35,36] on Au NCs described the use of thiolated ligands for capping. In both studies, diverse emissive colors were observed by optimizing the ligand or its concentrations. Several NC specimens are presented in this paper with various ligands, which have been already explored in many sensor studies. Thus, selection 
of suitable ligands and optimization of their concentration play vital roles in the luminescent property of NCs.

B. Quantum Yield $(\Phi)$ : The quantum yield $(\Phi)$ of the probe should be effectively tuned by optimizing the reaction conditions, functionalizing the appropriate ligands at affordable concentration, and selecting solvents for assay methods to maximize the application of luminescent M-NCs in analyte detection. For example, Aldeek and Deng et al. presented $\mathrm{Au}$ NCs with polyethylene glycol with zwitterion and L-arginine functionalization and revealed diverse quantum yields of $14 \%$ and $65 \%$ [37,38]. Prof. Mattoussi and Chowdhury's research $[39,40]$ on $\mathrm{Ag}$ NCs with diverse stabilizers demonstrated the enhancement of quantum yields. Lysozyme- and glutathione-stabilized $\mathrm{Cu}$ NCs have also been reported to have diverse quantum yields of $18 \%$ and $43 \%$, respectively, for LED applications [41,42]. Fernández et al. presented lipoic-acid-capped Pt NCs with 47\% quantum yields, which was due to the presence of a suitable stabilizer [43], thus confirming that an appropriate stabilizer affects the quantum yield or brightness of NCs.

C. Stability of NCs: Stability is an important property that must be optimized prior to performing assay studies. Researchers verify the stability of their probes by using suitable stabilizers, solvents, temperatures, and $\mathrm{pH}$ levels [44]. Taylor et al. theoretically proposed thermodynamic stability [45] for design of M-NC-based probes for sensory and bio-imaging studies.

D. Toxicity: The biological applications of M-NCs are attributed to toxicity optimization [46]. The probes must initially undergo MTT assay to authenticate their biocompatibility and intracellular permeability. Therefore, researchers have focused on developing less toxic M-NCs for drug delivery and imaging applications.

\section{AuNCs in Sensor Studies}

Among noble metal NCs, Au NCs seem more effective in biological and catalytic applications. $\mathrm{Au}$ NCs have been well utilized for detection of analytes, such as metal ions, anions, biomolecules, and DNA/RNA, and in in vitro/vivo cellular imaging of species. Here, we present a few examples of sensor applications. For metal ion sensors, Yang et al. developed lysine-stabilized Au NCs for detection of $\mathrm{Cu}^{2+}$ ions via fluorescence turn-off response (Figure 2). The results demonstrated that the method was highly sensitive, with a detection limit (LOD) of $0.8 \times 10^{-12} \mathrm{~mol} \cdot \mathrm{L}^{-1}$. In this study, the combination of Au NCs@Lys and Au NCs@BSA was utilized as a novel strategy for quantifying $\mathrm{Cu}^{2+}$ ions [47].

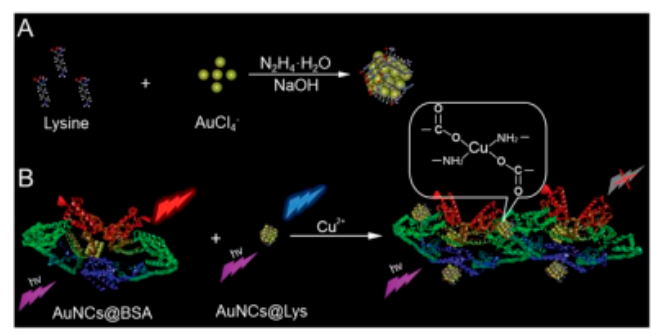

Figure 2. (A) Synthesis of Au NCs@Lys and (B) strategy for $\mathrm{Cu}^{2+}$ detection (Copyright Ref [47], Royal Society of Chemistry).

Using a similar approach, Deng et al. described biocompatible methionine-capped Au NCs (met-Au NCs) as a specific probe for detecting $\mathrm{Cu}^{2+}$ ions [48]. $\mathrm{Cu}^{2+}$ detection showed a linear range between $50 \mathrm{nM}$ and $8 \mu \mathrm{M}$ with a limit of $7.9 \mathrm{nM}$. The probe exhibited reversibility and improved selectivity among various metal ions and anions. These nanomolar LOD (limit of detection) with reversibility led to the development of such sensors in recent years. Metal-mediated Au NCs were further tuned to detect biomolecules via reversible fluorescent enhancement. For example, Wu et al. conveyed the "on-off-on" fluorescence recognition of $\mathrm{Cu}(\mathrm{II})$ and vitamin $\mathrm{C}$ [49]. Here, Au NCs 
were templated with bovine serum albumin (BSA) to visualize the near-infrared fluorescence with a quantum yield of $\sim 6.0 \%$; these templated Au NCs have been effectively applied in HeLa cellular imaging of $\mathrm{Cu}^{2+}$ and vitamin $\mathrm{C}$. Upon their functionalization with different precursors, Au NCs can specifically detect diverse metal ions.

Liu et al. presented the utility of $\alpha$-chymotrypsin A (CTRA-which is an important enzyme in medical research) functionalized $\mathrm{Au}$ NCs for fluorometric and colorimetric sensing of $\mathrm{Hg}^{2+}$ ions [50]. In this study, Au NCs were synthesized by a "green method" and transferred to a cellulose membrane by realizing the advantage of blotting technology. The results suggested that the method can be applied as an alternative analytical tool for $\mathrm{Hg}^{2+}$ detection in research on life sciences and pollution. Senthamizhan et al. demonstrated the real-time visual recognition of $\mathrm{Hg}^{2+}$ ions in water at ppt level by using Au NC-decorated polycaprolactone (PCL) nanofibers [51]. Several research groups have developed cost-effective precursors to obtain stable Au NCs for sensory studies. For instance, Prof. Li's group developed Au NCs stabilized by chicken egg white (CEW) for detection of $\mathrm{Hg}^{2+}$ ions [52]. These CEW-Au NCs selectively detected $\mathrm{Hg}^{2+}$ in the presence of $\mathrm{Cu}^{2+}$ ions by EDTA masking approach. Citrate-stabilized stannous ions ( $\mathrm{Sn}(\mathrm{II})$-citrate) have been used as reducing and capping agents to obtain $\mathrm{Au}$ NCs for simultaneous detection of $\mathrm{Cu}^{2+}$ and $\mathrm{Hg}^{2+}$ ions [53]. In this system, Chen et al. stated that Au NCs acted as dual spectroscopic probes that utilized both fluorescence (FL) quenched by $\mathrm{Cu}^{2+}$ and resonance light scattering (RLS) enhanced by $\mathrm{Hg}^{2+}$ ions.

Apart from $\mathrm{Cu}^{2+}$ and $\mathrm{Hg}^{2+}$ sensors, Au NCs with different stabilizers have also been used to detect other metal ions. Yang et al. reported red emitting $\mathrm{Au}_{7}(\mathrm{DHLA})_{2} \mathrm{Cl}_{2}$ clusters [54] with $3.6 \%$ quantum yield; the clusters were templated with dihydrolipoic acid (DHLA) and acted as a potential fluorescent sensor for $\mathrm{Fe}^{2+}$ with an LOD of $3.8 \mu \mathrm{M}(0.2 \mathrm{ppm})$. Moreover, this study proposed the dissociation-induced fluorescence quenching mechanism. Prof. Jin's group used 11-mercapto-undecanoic acid (11-MUA) capped Au NCs $(\Phi=2.4 \%)$ for exclusive detection of $\mathrm{Cr}$ (III) and $\mathrm{Cr}$ (VI) ions [55]. Upon the addition of $\mathrm{Cr}$ (III) to 11-MUA-Au NCs, the fluorescence intensity was quenched linearly between 25 and $10 \mathrm{mM}$ with an LOD of $26 \mathrm{nM}$. The probe also detected $\mathrm{Cr}(\mathrm{VI})$ in the presence of ascorbic acid as a reductant in aqueous solution. Baral et al. established the detection of $\mathrm{Fe}^{3+}$ ions by $\mathrm{Au}$ NCs obtained from CTAB protected gold nanorods by using reduced glutathione [56]. These methods confirmed the reversibility of Fe(III) sensor with sulfide ions.

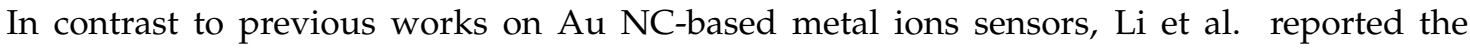
fluorescent "turn-on" detection of Ag(I) ions [57] by employing BSA-protected small gold nanoclusters $\left(\mathrm{Au}_{16}\right.$ NCs@BSA). As illustrated in Figure 3, upon the addition of Ag(I) ions to $\mathrm{Au}_{16}$ NCs@BSA, a blue shift and fluorescence enhancement were observed. This work proved that Au NCs may act as reductants for reducing $\mathrm{Ag}^{+}$into $\mathrm{Ag}^{0}$ and to form hybrid $\mathrm{Au} @ \mathrm{Ag} \mathrm{NCs}$.
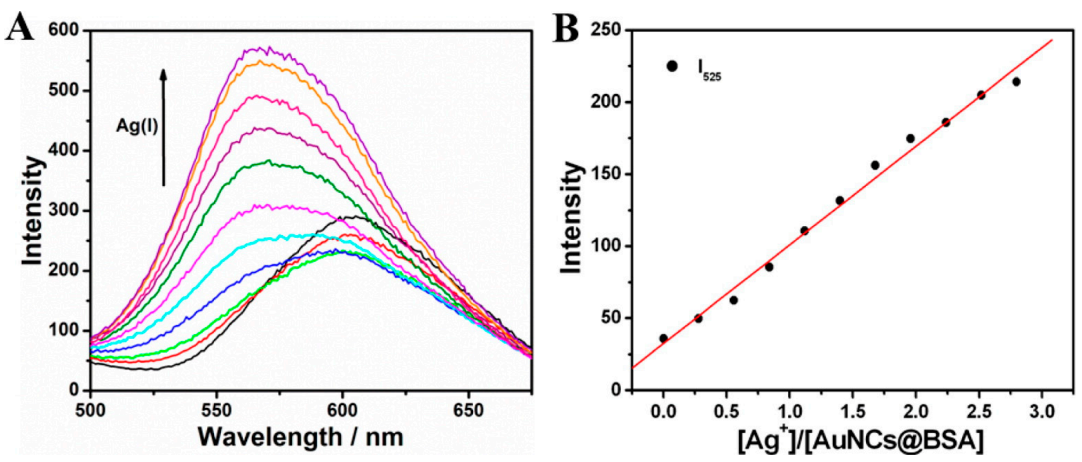

Figure 3. (A) Fluorescence spectra of $\mathrm{Au}_{16} \mathrm{NCs} @ \mathrm{BSA}(1 \mathrm{mg} / \mathrm{mL})$ in buffer solution ( $\left.\mathrm{pH} 7.5\right)$ measured $20 \mathrm{~min}$ after the addition of $\mathrm{AgNO}_{3}\left(\lambda_{\mathrm{ex}}=350 \mathrm{~nm}\right)$, from bottom to top the concentration increasing from 0 to $40.0 \mu \mathrm{M}$. (B) Plot of photoluminescence (PL) intensity at $525 \mathrm{~nm}$ vs the molar ratio of $\mathrm{Ag}^{+}$to $\mathrm{Au}_{16}$ NCs@BSA; the concentrations of $\mathrm{Ag}^{+}$are the same as in (A) (Copyright Ref [57], American Chemical Society). 
$\mathrm{Au}$ NCs with diverse precursors have also been used for selective recognition of anions. As presented in Figure 4, Liu et al. developed BSA-Au NCs for detection of $\mathrm{CN}^{-}$ions [58]. This work presented the fluorescence quenching of BSA-Au NCs induced by $\mathrm{CN}^{-}$ions with an LOD of $200 \mathrm{nM}$, which is $\sim 14$ times lower than the maximum cyanide level $\left(2.7 \times 10^{-6} \mathrm{M}\right)$ allowed in drinking water by the World Health Organization (WHO). Moreover, this sensor was relatively simple and did not require any complex synthesis or complex instruments.

Zhang et al. and Shojaeifard et al. developed and applied red emitting Au NCs with $\Phi$ values of 1.03 and $0.13 \%$ in $\mathrm{CN}^{-}$ion detection [59,60]. In these reports, L-amino acid oxidase (LAAOx) and L-glutathione (GSH) were used as agents to protect Au NCs. GSH-Au NCs [60] were initially titrated with copper(II) phthalocyanine [Cu(PcTs)]; analysis of the results revealed their turn-off effect on each other, leading to the recovery of $[\mathrm{Cu}(\mathrm{PcTs})]$ fluorescence in the presence of $\mathrm{CN}^{-}$ions and the decrease in the fluorescence intensity of gold nanoclusters (Au NCs). Thereafter, researchers successfully applied BSA-protected $\mathrm{Au}$ NCs as probes for identifying anions, such as hypochlorite $(\mathrm{HOCl})$, sulfide ion $\left(\mathrm{S}^{2-}\right)$, nitrite ion $\left(\mathrm{NO}_{2}{ }^{-}\right)$, and pyrophosphate ion $\left(\mathrm{P}_{2} \mathrm{O}_{7}{ }^{4-}, \mathrm{PPi}\right)$, with affordable linear detection ranges and limits [61-64]. Pyrophosphate ion $\left(\mathrm{P}_{2} \mathrm{O}_{7}{ }^{4-}\right.$, PPi) detection [64] was a fluorescent "turn-on" sensor via the BSA-Au NCs-Cu ${ }^{2+}$ mediated complex system. Sun et al. reported a similar approach for detecting PPi by forming a $\mathrm{Fe}^{3+}$ complex [65] with GSH/MUA protected clusters (Au NCs@GSH/MUA; $\Phi=3 \%$ ).

Acetylcysteine-stabilized gold NCs (ACC@Au NCs) with an excellent quantum yield of 14\% have been recognized as selective and sensitive fluorescent sensors for detecting hydrogen sulfide $\left(\mathrm{H}_{2} \mathrm{~S}\right)$ [66]. Zhang et al. reported on $\mathrm{H}_{2} \mathrm{~S}$ detection over other anions, amino acids, and thiols (Figure 5). The ACC@Au NCs revealed a linear response between 0.002 and $120 \mu \mathrm{mol} \cdot \mathrm{L}^{-1}$ with an LOD of $1.8 \mathrm{nmol} \cdot \mathrm{L}^{-1}$. These impressive findings have highlighted Au NC-based biosensors.

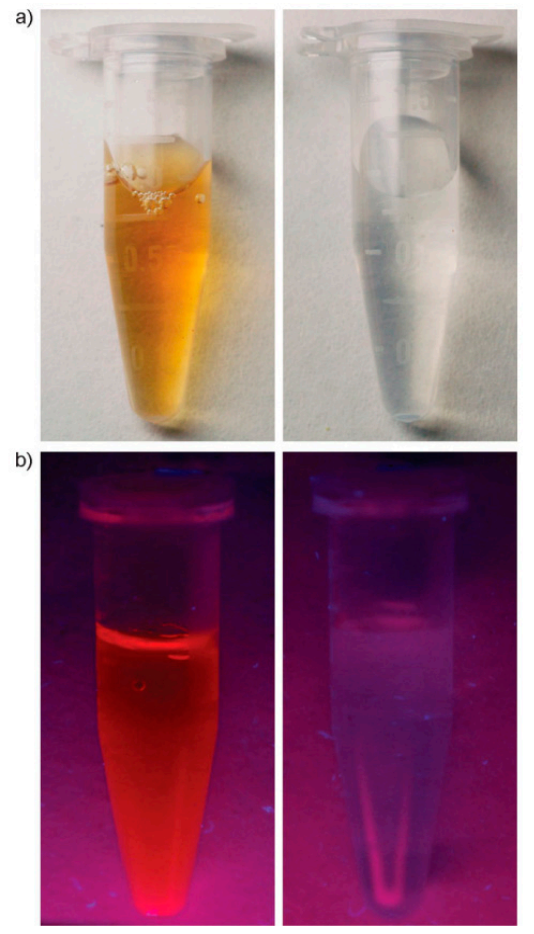

Figure 4. (a) Aqueous solution of Au NCs before (left) and after (right) addition of $5 \times 10^{-3} \mathrm{M}$ cyanide. (b) Fluorescence of the aqueous solution of Au NCs before and after addition of $5 \times 10^{-3} \mathrm{M}$ cyanide under UV light at $365 \mathrm{~nm}$ (Copyright Ref [58], WILEY publications). 


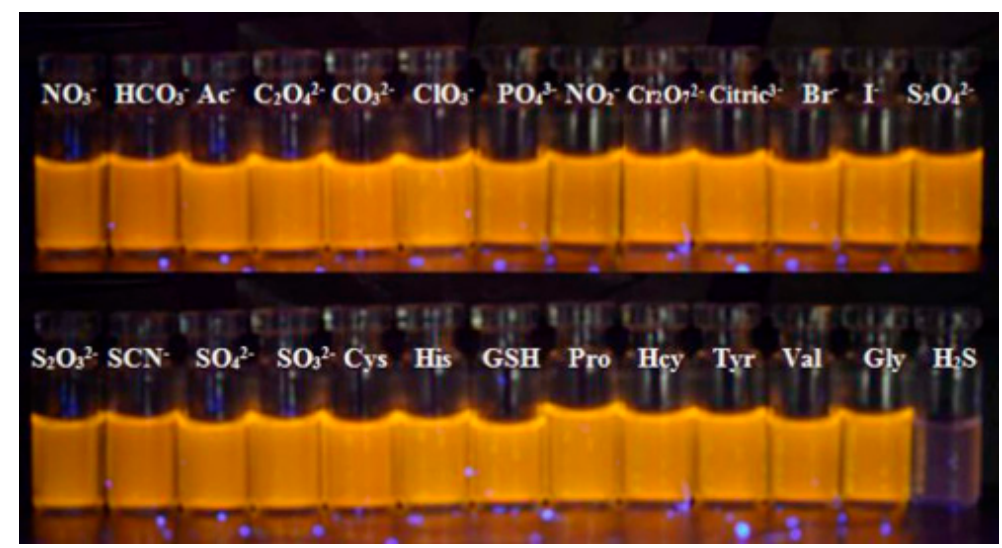

Figure 5. Photographs of acetylcysteine-stabilized gold NCs (ACC@Au NCs) with different analyte solutions viewed under UV light at $365 \mathrm{~nm}$ (Copyright Ref [66], ELSEVIER publications).

In addition to the detection of metal ions or anions, Au NCs have been exclusively applied for identification of biomolecules. BSA-templated Au NCs were effectively used as fluorescent probes for detecting cholesterol and dopamine $[67,68]$. In these studies, the utilized red emissive BSA-Au NCs became non-emissive during analyte recognition. Moreover, the LODs of cholesterol and dopamine were estimated to be $12 \mu \mathrm{M}$ and $0.622 \mathrm{nM}$, respectively. Wen et al. utilized horseradish peroxidase (HRP)-templated Au NCs for detection of hydrogen peroxide [69]. The linear assay range was $100 \mathrm{nM}$ to $100 \mu \mathrm{M}$ with an LOD of $30 \mathrm{nM}$. This study can be extended to other functional proteins to produce dual functional NCs by mixing the functions of biomolecules and nanoclusters via a simple one-step synthesis. In addition to these sensor studies, $\mathrm{Ni}^{2+}$ ion-mediated BSA-Au NCs were employed as attractive probes for "turn-on" detection of histidine over other amino acids [70]. This work used human urine samples for real-time monitoring, and the recoveries ranged from $95 \%$ to $104 \%$. Dai et al. presented a metal-mediated approach, in which $\mathrm{Hg}^{2+}$-mediated BSA-Au NCs were used for determination of melamine [71]. The sensor LOD decreased to $0.15 \mathrm{mM}$ (which is 130 times lower than the estimated value by the US Food and Drug Administration). This work also demonstrated the practicality of melamine detection in raw milk and milk powder.

Song and Chen et al. reported the use of peptide- and BSA-capped Au NCs for sensing protein kinase activity (which plays a significant role in adjusting cellular biological processes) and quercetin (a flavonoid present in Chinese Herbal Medicine), respectively [72,73]. During sensor titration, both cases revealed fluorescence quenching with LODs of $0.004 \mathrm{U} \cdot \mathrm{mL}^{-1}$ ( $\mathrm{U}$ is defined as the enzyme quantity that liberates $1 \mu \mathrm{g}$ or $\mu \mathrm{M}$ of the product) and $1.8 \times 10^{-8} \mathrm{~mol} \cdot \mathrm{L}^{-1}$, correspondingly. Wu et al. presented the use of GSH-Au NCs for detecting heparin (which plays a crucial role in the regulation of various biological processes, such as cell growth and differentiation, inflammation, immune defense, lipid transport, and metabolism) [74]. This report demonstrated the detection of heparin in the presence of cetyl-trimethyl ammonium bromide (CTAB, fluorescence enhancing agent) with a limit of $0.075 \mathrm{mg} \cdot \mathrm{mL}^{-1}$. This probe (GSH-Au NCs) was also applied to detect human serum samples.

Bioimaging studies of fluorescent Au NCs have also gained considerable interest in recent years. In view of their fluorescent quantum yield, biocompatibility, and photostability, template-protected $\mathrm{Au}$ NCs have been utilized as novel optical probes for in vitro and in vivo fluorescence imaging studies [75]. For example, purine-stabilized green fluorescent Au NCs with $1.2 \%$ quantum yield in methanol were used in cell nuclei imaging studies [76].

In a previous study, Au NCs were treated with HeLa, A498, Schwann, and L929 cell lines to confirm their nucleus targeting ability; the results showed green emission from their nuclei (Figure 6). Wang et al. demonstrated the "turn-on" bio-imaging ability of near-infrared (NIR) fluorescent Au NCs $(\Phi=7.7 \%)$ /graphene oxide nanocomposites in cancer cells and small animals [77]. In a similar manner, Caenorhabditis elegans (free-living round worms in temperate soil environments that lack respiratory 
and circulatory systems) and reactive oxygen species (ROS) were imaged with mulidendate thiolated tryptophan- and BSA-capped Au NCs [78,79]. In both studies, the NIR-fluorescence had quantum yields of $6 \%$ and $5.8 \%$ and was effectively used in the imaging readings. Biswas et al. employed $\mathrm{Au}$ NCs containing polymeric microcapsules to investigate the intracellular ratiometric fluorescence biosensing response to hydrogen peroxide [80].

As in the case of organic fluorescent probes, Au NC-based probes also acted as $\mathrm{pH}$-sensitive probes in chemo- and bio-sensor investigations [81,82]. For example, Wu et al. reported a dual-emission fluorescent probe consisting of BSA-Au NCs and fluorescein-5-isothiocyanate (FITC) as temperature and $\mathrm{pH}$ sensors [83]. The probe displayed temperature sensing from $21^{\circ} \mathrm{C}$ to $41^{\circ} \mathrm{C}$ and $\mathrm{pH}$ from 6.0 to 8.0. Ali et al. indicated the use of BSA-Au NCs as pH-selective sensors within the pH range of 5 to 9 [84].

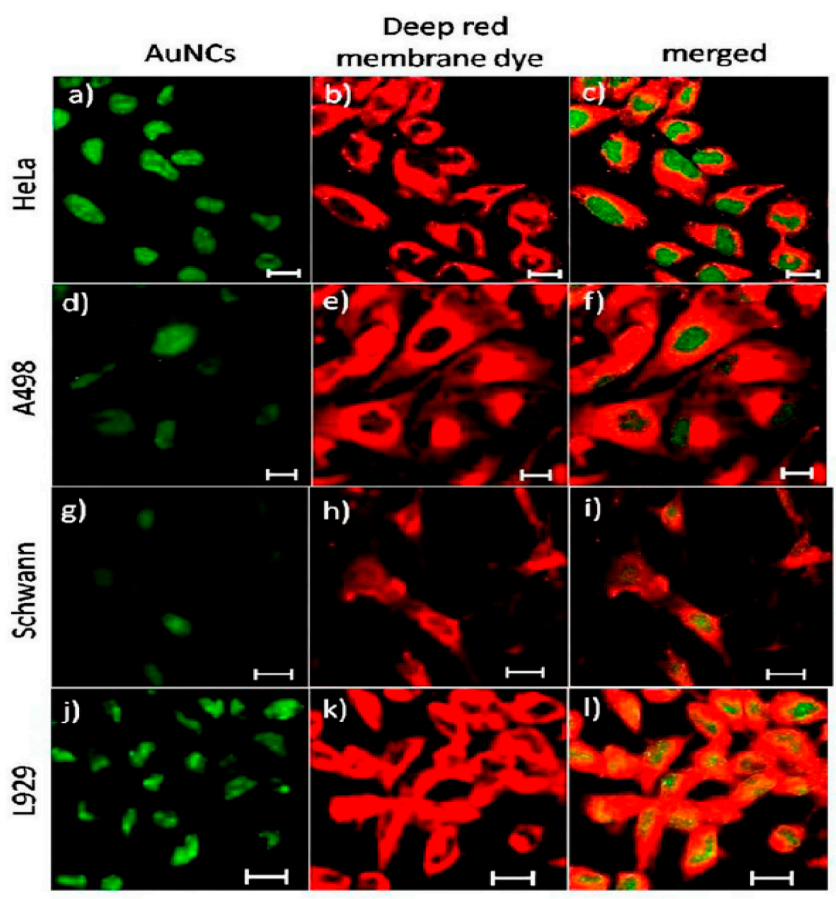

Figure 6. Confocal laser scanning microscope images of four different cell lines after treatment with green emitting AuNCs $\left(\lambda_{\mathrm{em}}=510 \mathrm{~nm}\right)$; deep red plasma membrane dye exhibits red emission $\left(\lambda_{\mathrm{em}}=633 \mathrm{~nm}\right)$, which is used as a reference for cell membrane staining. (a-c) Images of Au NCs, deep red plasma membrane dye, and their merged images of HeLa cells, respectively. (d-f) Images of A498 cells; ( $\mathbf{g}-\mathbf{i})$ images of Schwann cells; (j-1) images of L929 cells (scale bar corresponds to $10 \mu \mathrm{m}$ ) (Copyright Ref [76], American Chemical Society).

\section{Ag NCs as Sensory Probes}

As noble metal NCs, Ag NCs have attracted the attention of the scientific community because of their extraordinary sensory performance. Given their high fluorescent quantum yield, biocompatibility, and photo and chemo stability, Ag NCs have been applied in various sensory investigations. Luminescent Ag NC-based metal ions sensors are the most notable [85]. In the past decade, Shang et al. elucidated Ag NCs-based fluorescent detection of $\mathrm{Cu}(\mathrm{II})$ ions [86] in a linear range of $1.0 \times 10^{-8}$ to $6.0 \times 10^{-6} \mathrm{M}$; the obtained LOD was found to be as low as $8 \mathrm{nM}$. In this work, poly(methacrylic acid) (PMAA) was utilized as a template and stabilizer. Fluorescence quenching-based recognitions of $\mathrm{Cu}$ (II) ions have been achieved by hyper branched poly-ethyleneimine (hPEI)- and amido black 10B (AB)-stabilized Ag NCs $(\Phi=1.5 \%$ and 0.2) [87,88]; the LODs were estimated as 10 and $4 \mathrm{nM}$, respectively. Sun et al. presented GSH-passivated Ag NCs for specific fluorimetric and colorimetric recognition of $\mathrm{Cu}$ (II) ions [89]. This work presented both the fluorimetric and colorimetric responses of GSH-Ag NCs to $\mathrm{Cu}(\mathrm{II})$ ions (Figure 7) and demonstrated the reversibility in the presence of EDTA. 
These GSH-Ag NCs showed subnanomolar LODs in both responses $(0.050 \mathrm{nM}$ in fluorimetric and $0.60 \mathrm{nM}$ in colorimetric) with reasonable linear ranges.

Adhikari et al. reported on $\mathrm{Hg}$ (II) ion detection in water by dihydrolipoic acid (DHLA) stabilized Ag NCs ( $\Phi=2 \%$ in water) [90]. This work established $\mathrm{Hg}$ (II) detection via the fluorescence quenching of NIR-Ag NCs. The linear range was from $10^{-8}$ to $10^{-5} \mathrm{M}$ with an LOD of $10^{-10} \mathrm{M}$, which is lower than the maximum permissible limit in drinking water (2 ppb, $10 \mathrm{nM})$. DNA-templated Ag NCs were successfully applied in $\mathrm{Hg}$ (II) sensor studies by MacLean and Yin's research groups [91,92]. In both investigations, diverse DNA sequences were utilized, resulting in fluorescence quenching and enhanced responses during $\mathrm{Hg}$ (II) ion recognition. The LODs of the $\mathrm{Hg}$ (II) sensors by both probes were estimated as $4 \mathrm{nM}$ and $0.08 \mathrm{nM}$, respectively. Lee et al. also presented DNA-based Ag clusters $\left(\mathrm{Cyt}_{12}-\mathrm{Ag} \mathrm{NCs} ; \Phi=43.9 \%\right)$ for detection of $\mathrm{Ag}(\mathrm{I})$ ions [93]. In this study, $\mathrm{Cyt}_{12}-\mathrm{Ag}$ NCs validated the recognition of $\mathrm{Ag}(\mathrm{I})$ ions through the shift of the fluorescence response from red to green with an LOD of $10 \mathrm{nM}$. Furthermore, the $\mathrm{Ag}(\mathrm{I})$ sensor selectivity was confirmed through the detection of $\mathrm{Ag}^{+}$in Silmazin (dermatological burn ointment containing silver sulfadiazine).

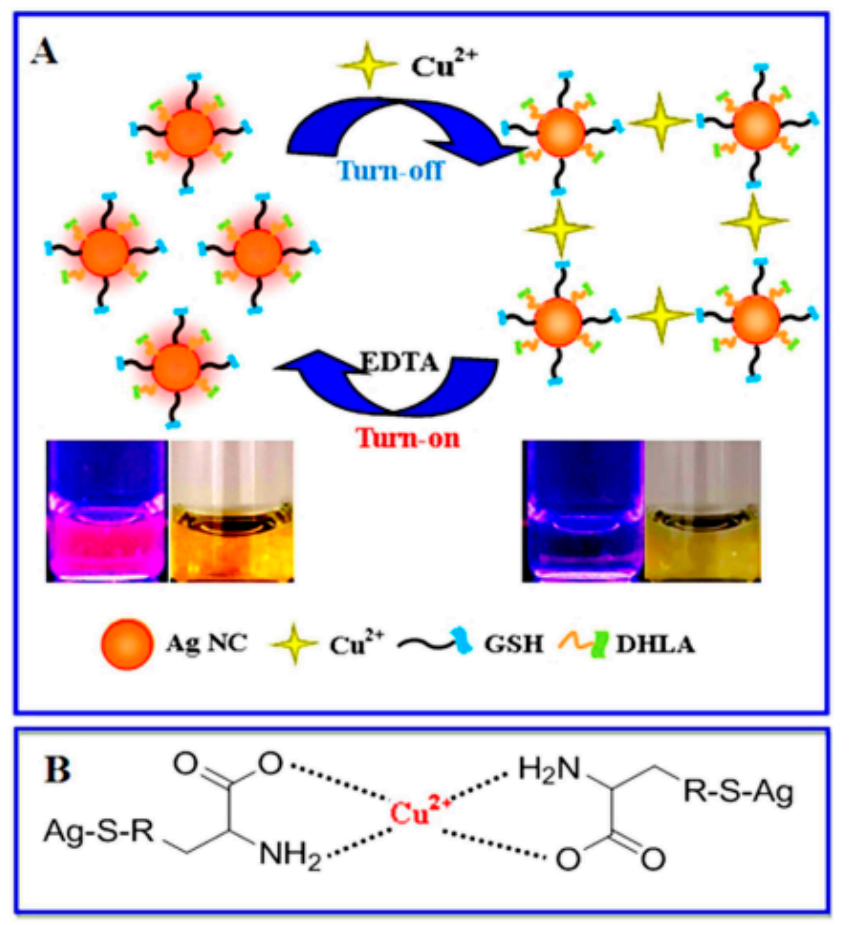

Figure 7. Schematic illustration of (A) the reversible fluorimetric and colorimetric detection mechanism and procedure of L-glutathione (GSH)-passivated Ag NCs toward the fluorimetric and colorimetric assays for $\mathrm{Cu}^{2+}$ ions (insert: the photographs of corresponding products), and (B) the chelating interaction between $\mathrm{Cu}^{2+}$ ions and GSH of GSH-passivated Ag NCs (Copyright Ref [89], Nature Publications).

Polyethyleneimine (PEI)- and GSH-capped Ag NCs have been extensively applied for detection of $\mathrm{Cr}(\mathrm{VI}), \mathrm{Fe}(\mathrm{III})$, and $\mathrm{Pb}(\mathrm{II})$ ions with affordable LODs [93-96]. However, GSH@Ag NCs for detection of $\mathrm{Pb}$ (II) ions were synthesized by a sonochemical method [96] rather that a wet chemical route. These probes exhibited fluorescence quenching during determination of metal ions. Liu et al. used DNA-stabilized Ag NCs for ratiometric recognition of mercury and copper ions [97]. The linear ranges of $\mathrm{Hg}^{2+}$ and $\mathrm{Cu}^{2+}$ were from $0.01 \mu \mathrm{M}$ to $0.5 \mu \mathrm{M}$ and from $0 \mu \mathrm{M}$ to $1.0 \mu \mathrm{M}$ with corresponding LODs of $1.03 \mathrm{nM}$ and $2.77 \mathrm{nM}$, respectively. This work also discriminated the detections in the presence of an EDTA chelating reagent. To date, many studies have developed probes for detection of other analytes. 
Ag NCs have also been exploited for anion discovery. Chen et al. developed blue-emitting GSH-stabilized Ag NCs $(\Phi=1.9 \%)$ through a sonochemical method and successfully applied them in sulfide ion $\left(\mathrm{S}^{2-}\right)$ detection [98]. The recognition of $\mathrm{S}^{2-}$ ions also revealed fluorescent quenching with an LOD of $2 \mathrm{nM}$. Gao et al. performed $\mathrm{S}^{2-}$ ion detection by utilizing denatured lysozyme-capped clusters (dLys-Ag NCs) [99]. They tuned the molar ratios of $\mathrm{AgNO}_{3}$ to lysozyme (1:1, 2:1, and 4:1 for synthesizing dLys-Ag NCs $\mathbf{1}, \mathbf{2}$, and 3, respectively) and then used them in sensor titrations. Furthermore, $\mathrm{S}^{2-}$ ion detection via "turn-off" and "turn-on" responses was realized by dLys-Ag NCs (1) and dLys-Ag NCs (3), respectively, with LODs of 0.2 and $0.6 \mu \mathrm{mol} \cdot \mathrm{L}^{-1}$, respectively. Moreover, these probes were effective in real water samples. Huang et al. employed Ag NC-capped silica nanoparticles $\left(\mathrm{SiO}_{2} @ \mathrm{Ag} \mathrm{NCs}\right)$ for photoluminescent ratiometric quantification of $\mathrm{S}^{2-}$ and $\mathrm{I}^{-}$ions, with LODs of 62 and $57 \mathrm{nM}$, respectively [100].

Hyperbranched polyethyleneimine-protected silver nanoclusters (hPEI-Ag NCs) were reported by Chen et al. for recognition of nitrite $\left(\mathrm{NO}_{2}{ }^{-}\right)$ion [101]. The involved $\mathrm{NO}_{2}{ }^{-}$sensor was validated by the fluorescent "turn-off" response of the cluster material. This study used the nitrite- $\mathrm{H}_{2} \mathrm{O}_{2}$ chemical reaction as a detection principle. The LOD of the sensor was estimated as $100 \mathrm{nM}$ with a linear range of 0 to $7 \mu \mathrm{M}$. Wang et al. proposed a solvent induced fluorescent enhancement strategy for identification of $\mathrm{I}^{-}$ions in urine samples [102].

In this work, upon addition of isopropyl alcohol (IPA), the fluorescence of GSH-Ag NCs was enhanced and then addressed in $\mathrm{I}^{-}$detection via the "turn off" response with the limit of $0.5 \mathrm{nM}$ (Figure 8). This probe was also applied in urine sample analysis with an LOD of $7.5 \mathrm{nM}$. The simultaneous detection of iodide $\left(\mathrm{I}^{-}\right)$and bromide $\left(\mathrm{Br}^{-}\right)$ions was realized by carboxymethyl dextran (CMD)-stabilized Ag NCs [103]. In this report, the probe was applied to detect $\mathrm{I}^{-}$in


measured in a Britton-Robinson (BR) buffer solution. Liu et al. used lysozyme-stabilized Ag NCs (dLys-Ag NCs) as probes for the ratiometric detection of hydrogen peroxide and hydroxyl radical with live cell imaging [104]. The linear detection range for $\mathrm{H}_{2} \mathrm{O}_{2}$ was from 0.8 to $200 \mu \mathrm{mol} \cdot \mathrm{L}^{-1}$ with an LOD of $0.2 \mu \mathrm{mol} \cdot \mathrm{L}^{-1}$. This probe was also applied in $\mathrm{H}_{2} \mathrm{O}_{2}$-generated oxidase-based biosensing. For instance, this probe involved the discovery of glucose and acetylcholine chloride with LODs of 0.6 and $0.8 \mu \mathrm{mol} \cdot \mathrm{L}^{-1}$. Moreover, the hydroxyl radical fluctuation was verified by cellular imaging. Thus, the development of such probes was still focused on the effective utility in the findings of hydroxyl-induced oxidative damage in proteins.

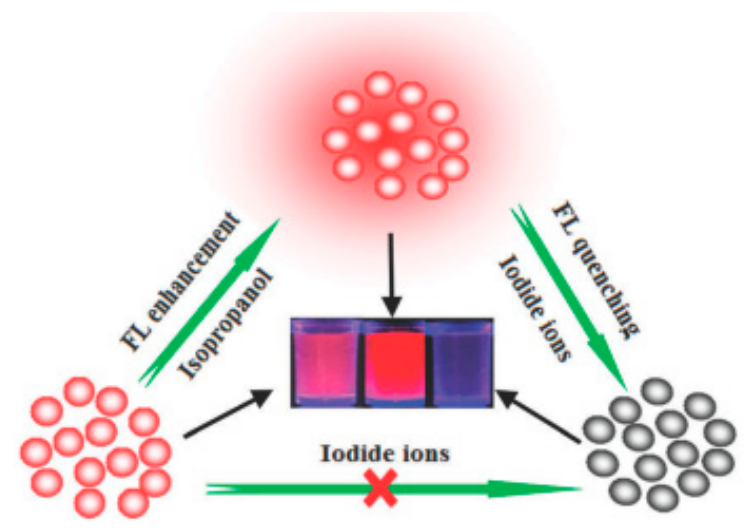

Figure 8. Schematic illustration of isopropyl alcohol (IPA)-triggered fluorescence enhancement of the Ag NCs and then fluorescence turning-off induced by iodide ions (Copyright Ref [102], Royal Society of Chemistry).

Templated Ag NCs have also been significantly applied in the detection of biologically important species. For example, Liu et al. used L-GSH stabilized Ag NCs with a quantum yield of $9.09 \%$ for the chiral recognition of amino acids [105]. They used the fast and green micro wave-assisted approach to 
develop water-soluble fluorescent L-GSH-Ag NCs. In addition, DNA-templated AgNCs $(\Phi=18.6 \%)$ were used as probes for identifying thiol compounds, such as GSH, cysteine (Cys), and homocysteine (Hcy) via fluorescent enhancement [106]. This report also revealed the order of enhancement as Hcy > GSH > Cys. Zhang et al. employing polyethyleneimine-capped silver nanoclusters (PEI-Ag NCs; $\Phi=3.81 \%$ ) in the assay of important biothiol compounds in the presence of various interferences [107]. This sensor probe was more specific for the identification of Cys, Hcy, and GSH via fluorescent "turn-off" (Figure 9). The obtained linear ranges for Cys, Hcy, and GSH were 0.1-10 mM, 0.1-10 mM, and 0.5-6 mM, respectively, with the LODs of 42, 47, and $380 \mathrm{nM}$. Moreover, during the addition of biothiol compounds to the probe, color changes from colorless to red-brown were observed, which can be visualized through naked eyes without any complex instruments.

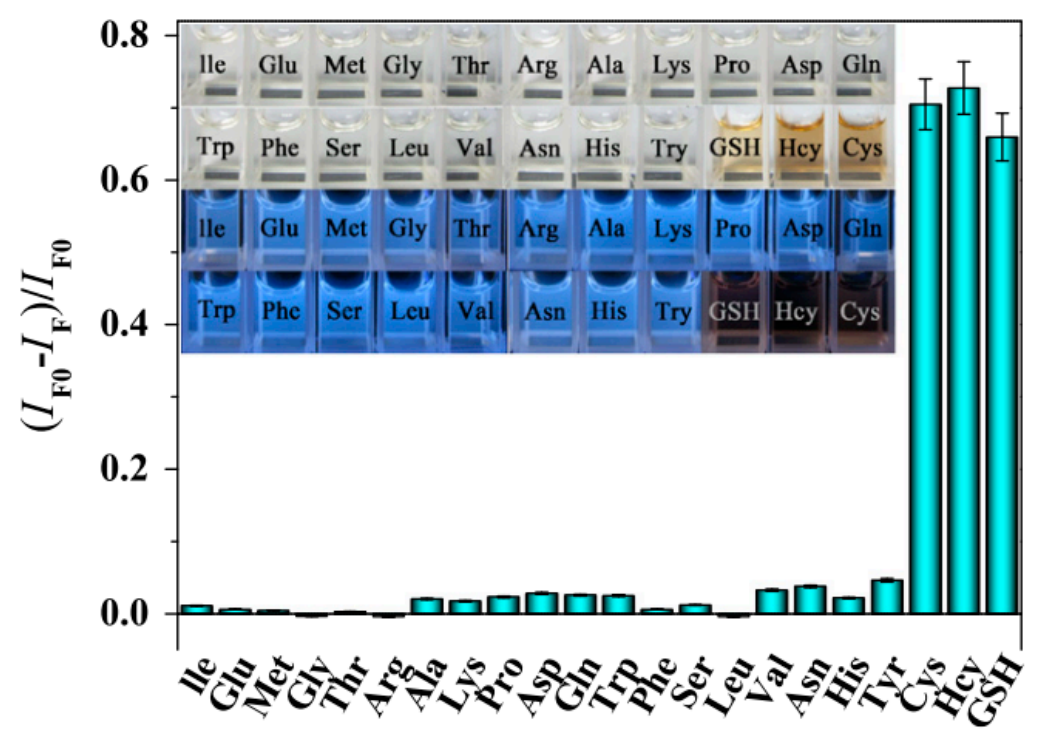

Figure 9. The responses of different amino acids to polyethyleneimine (PEI)-capped Ag NCs: Cys, Hcy and GSH $(10 \mathrm{mM})$, other 19 amino acids $(100 \mathrm{mM})$. The picture inserted shows the color and fluorescence change of Ag NCs to different amino acids (300 mM) (Copyright Ref [107], ELSEVIER publications).

In view of the requirement of specific analyte sensors, Yuan et al. exploited GSH-Ag NCs $(\Phi=4.2 \%)$ for Cys detection [108]. Red-emitting GSH-Ag NCs were used for Cys detection via PL quenching over 19 other non-thiol containing amino acids with an LOD of $3 \mathrm{nM}$. Zhu et al. used the GSH-Ag NCs probe by controlling the molar ratio between Ag and glutathione for Cys detection through the tunable dual-emission fluorescent sensitivity [109]. For cluster-based biomolecule detection, Dong et al. reported on the discovery of urea and glucose by utilizing GSH-Ag NCs [110]. The GSH-Ag NCs displayed $\mathrm{pH}$ switchable agglomeration, leading to fluorescent quenching in the $\mathrm{pH}$ range of 3.57-8.05. This ability was beneficial for the sensing of urea and glucose through the "off-on" responses. The detections had linear ranges of $5-170 \mu \mathrm{M}$ and $0.3-13 \mathrm{mM}$ with LODs of $10 \mathrm{nM}$ and $10 \mu \mathrm{M}$, respectively.

In this footpath, Jin et al. used chromotropic acid (CTA) and layered double hydroxide nanosheets-functionalized Ag NCs (CTA-Ag NCs/LDH; $\Phi=12.08 \%$ ) as an effective "off-on" sensor for melamine [111]. This probe can determine melamine in the concentration range of $0.03 \mathrm{mM}$ to $0.1 \mathrm{mM}$ with an LOD of $4 \mathrm{nM}$. Chen et al. realized fluorometric "turn-on" glucose detection by Ag NCs based on the Fenton reaction, which can trigger the clusters [112]. This approach is a new strategy for glucose detection. Mao et al. used polyethyleneimine-capped Ag NCs combined with $\mathrm{Cu}^{2+}$ ions, which act as a metal mediated precursor for the selective recognition of quinolones present in biologically important antibiotics [113]. This assay presented the "turn-on" sensor for the trace detection of quinolones with the use of a PEI-Ag NCs-Cu ${ }^{2+}$ system with good linear ranges and low LODs. 
Similar to small-biomolecules detection, DNA-templated Ag NCs with a high fluorescent quantum yield of $\sim 60 \%$ have also been applied in the recognition of specific proteins, such as thrombin [114]. Zhou et al. repeatedly used the DNA aptamer stabilized yellow emissive Apt-Ag NCs ( $\Phi$ value of $\sim 17 \%$ ) for the selective detection of prion protein [115]. The probe confirmed the higher selectivity to prion $\left(\mathrm{PrP}^{\mathrm{c}}\right)$ than that to other proteins, such as HSA, BSA, lysozyme, thrombin, and pepsin, at 10 -fold higher concentrations than $\mathrm{PrP}^{\mathrm{c}}$. In the same way, DNA-Ag NCs have been successfully used in the selective determination of bleomycin (glycopeptide-derived antibiotics isolated from Streptomyces verticillus), which was then applied in cancer treatment [116]. However, the probe became more active in the presence of $\mathrm{Fe}^{2+}$ ions. Moreover, the linear detection range of bleomycin was estimated at 100-400 nM with an LOD of $54 \mathrm{nM}$. In a similar manner, red fluorescent Cys-modified maltose-containing Ag NCs $(\Phi=3 \%)$ were synthesized by Basiruddin et al. and used in the detection of glycoprotein with HeLa cell labeling [117].

Apart from the detection of metal ions, anions, biomolecules, and proteins, templated Ag NCs were also well consumed for the identification of nucleic acid as mentioned below. DNA-templated Ag NCs were used in the detection of microRNA by Vosch and Ye's research groups using "turn-off" and "turn-on" responses, respectively [118,119]. Among them, the turn on response of DNA-Ag NCs to microRNA (miR-141) was seemingly more remarkable with an LOD of 2 aM (attomolar). In a similar response, DNA discoveries were established by Prof. Wang and Zhang's research reports with the utilization of DNA-Ag NCs [120,121]. In both cases, the linear ranges and LODs remain interesting. Hence, DNA-templated Ag NCs offers an efficient platform for detection of a wide spectrum of analytes.

As validated by $\mathrm{Au}$ NCs, templated Ag NCs are also being applied in bio-imaging and pH-sensing studies. The DNA-Ag NCs $(\Phi=39.7 \%)$ were efficiently used in bio-imaging readings in HeLa cells by Zhu and co-workers [122]. Guével et al. reported the GSH-Ag NCs ( $\Phi$ value of $>60 \%$ ) with blue-green, yellow, and red emissions, which was further used in bio-imaging of epithelial lung cancer cells (A549); hence, its application was proposed in biomolecular interaction diagnostics [123]. Qu et al. described the hyperbranched PEI-capped $\operatorname{Ag}$ NCs $(\Phi=3.8 \%)$ as highly sensitive fluorescent and colorimetric $\mathrm{pH}$ sensors [124], in which, upon increasing acidity, the probe visualizes color changes from colorless to a colored state. On the other hand, fluorescence enhancement was observed at higher $\mathrm{pH}$ values. As a striking input to sensor research, $\mathrm{He}$ and Willner's research studies proved the uses of BSA-Ag NCs and DNA-Ag NCs for the detection of p-nitrophenol and nitroaromatic or RDX explosives, respectively $[125,126]$. Both investigations proved that the fluorescent-quenching responses and their LODs were in nano- and picomolar levels, correspondingly.

\section{Sensor Applications of Cu NCs}

Analogous to $\mathrm{Au}$ and Ag NCs, templated non-noble Cu NCs also acted as effective fluorescent probes and were regarded in various chemo-and biosensory studies as described in this section. They have also been used by researchers as attractive candidates for the determination of metal ions. For example, Prof. Huang and Mukherjee's research reports on $\mathrm{Cu}$ NCs witnessed its application in the detection of $\mathrm{Fe}^{3+}$ ions via fluorescent quenching $[127,128]$. To stabilize the $\mathrm{Cu} \mathrm{NCs}$, they used tannic acid and glutathione (GSH) as templates, respectively. Impressively, both Cu NCs exhibited blue emission with quantum yields of $14 \%$ and $6 \%$, correspondingly. Furthermore, the detection of $\mathrm{Fe}^{3+}$ in both studies evidenced good linearity with LODs of 10 and $25 \mathrm{nM}$, individually. In this way, Liu et al. presented a hyperbranched PEI-protected copper nanoclusters (hPEI-Cu NCs; $\Phi=7.9 \%$ ) conjugated to the surface of silica-coated CdSe quantum dots (QDs) for the ratiometric detection of $\mathrm{Cu}^{2+}$ ions [129]. Here, the fluorescence of the probe drastically quenched between the linear range of $22 \mathrm{nM}-8.8 \mu \mathrm{M}$ with an LOD of $8.9 \mathrm{nM}$.

Furthermore, glutathione (GSH)-capped Cu NCs $(\Phi=10.6 \%)$ were applied as a fluorescent probe for sensitive and selective acknowledgement of $\mathrm{Hg}^{2+}$ in water and foodstuffs by $\mathrm{Hu}$ and co-workers [130]. In this work, upon the accumulation of $\mathrm{Hg}^{2+}$ ions, the fluorescence of GSH-Cu NCs 
was quenched between the linear range from $10 \mathrm{nM}$ to $10 \mu \mathrm{M}$ with an LOD of $3.3 \mathrm{nM}$. Interestingly, the above probe with a quantum yield of $5.3 \%$ was also developed through sonochemical synthesis and consumed in fluorescent "turn-off" sensing of $\mathrm{Pb}^{2+}$ ions with an LOD of $1.0 \mathrm{nM}$ [131]. On the other hand, Bing-Yan et al. represented the employment of GSH-Cu NCs in fluorescent "turn-on" recognition of $\mathrm{Pb}^{2+}$ ions [132]. However, the linear concentration of $\mathrm{Pb}^{2+}$ was lies between 200-700 $\mu \mathrm{M}$, with an LOD of $106 \mu \mathrm{M}$. In this course, Goswami and co-workers represented the BSA-capped $\mathrm{Cu}$ NCs (CuQC@BSA) towards the selective fluorescent "on-off" detection of $\mathrm{Pb}^{2+}$ ions [133]. Here, the probe has a quantum yield of 0.15 and evidenced the aggregation-induced quenching with $\mathrm{Pb}^{2+}$ ions in the presence of other interferences. The development of diverse fluorescent $\mathrm{Cu}$ NCs toward sensory application is a more exciting concept. In this context, Prof. Huang's research group attested dithiothreitol (DTT)-capped Cu NCs (DTT-Cu NCs) with orange fluorescence for the determination of $\mathrm{Al}^{3+}$ ions [134]. The detection mechanism was based on the aggregation-induced fluorescence enhancement with $\mathrm{Al}^{3+}$ ions. Notably, the linear relationship of DTT-Cu NCs with $\mathrm{Al}^{3+}$ ranged from $0.01 \mu \mathrm{M}$ to $7 \mu \mathrm{M}$ with an LOD of $0.01 \mu \mathrm{M}$. Similar to the above report, based on the aggregation-induced emission enhancement, $\mathrm{Zn}^{2+}$ ion discovery was proposed by GSH-Cu NCs $(\Phi=1.3 \%)$ [135] as illustrated in Figure 10. This work was also proven through cellular imaging studies. Further, the detection range of $\mathrm{Zn}^{2+}$ was found to be from $4.68 \mu \mathrm{M}$ to $2240 \mu \mathrm{M}$ with an LOD of $1.17 \mu \mathrm{M}$. During $\mathrm{Zn}^{2+}$ determination, the $\Phi$ value increased to $6 \%$.

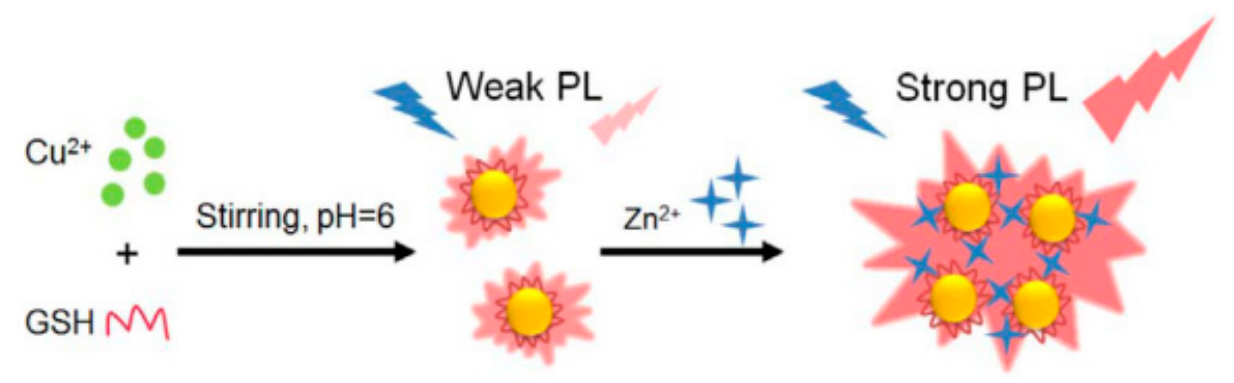

Figure 10. Schematic illustration of the preparation of GSH-capped $\mathrm{Cu}$ NCs and the aggregation induced PL enhancement of Cu NCs in the presence of $\mathrm{Zn}^{2+}$ (Copyright Ref [135], Elsevier publications).

Similar to metal ion sensors, precursor-stabilized $\mathrm{Cu}$ NCs were successfully used in the sensory investigation of anions as follows. Li et al. showed the fluorescent "turn-off" detection of $\mathrm{S}^{2-}$ ions by using cysteine-capped $\mathrm{Cu}$ NCs (Cys-Cu NCs) with real time applications in "Fart Bomb" samples [136]. The probe proposed the linear range from $0.2 \mu \mathrm{M}$ to $50 \mu \mathrm{M}$ with an LOD of $42 \mathrm{nM}$. Khonkayan et al. reported an impressive work for determination of $\mathrm{CrO}_{4}{ }^{2-}$ by 4,6-diamino-2-mercaptopyrimidine-protected Cu NCs (DAMP-Cu NCs) [137]. Under optimized conditions, DAMP-Cu NCs has a linear response between the chromate concentration range of 1-7 $\mu \mathrm{M}$ with an LOD of $0.31 \mu \mathrm{M}$. In a similar response, PEI-templated copper nanoclusters (Cu NCs) have been used in the recognition of $\mathrm{I}^{-}$ions between $0 \mu \mathrm{M}$ and $10 \mu \mathrm{M}$ linear range with an LOD of $100 \mathrm{nM}$ [138]. Impressively, the obtained results were validated by urine sample analysis.

A contribution to anion sensor, stabilizer-free $\mathrm{Cu} N C s$ was made in the detection of $\mathrm{NO}_{2}{ }^{-}$ions by Qiu and co-workers [139] as illustrated in Figure 11. The probe witnessed the linear ranges varying from $12.5 \mathrm{nM}$ to $125 \mu \mathrm{M}$ and from $125 \mu \mathrm{M}$ to $5000 \mu \mathrm{M}$ with an LOD of $3.6 \mathrm{nM}$. Zhou et al. presented the GSH-Cu NCs $(\Phi=8.6 \%)$ as the sensory probe for $\mathrm{NO}_{2}{ }^{-}$ions between the range of 1-100 mM, with an LOD of $0.3 \mu \mathrm{M}$ [140]. Moreover, it was applied in real water sample investigations. Instead, thiosalicylic acid-capped $\mathrm{Cu}$ NCs with a quantum yield of $13.2 \%$ were engaged in the $\mathrm{pH}$-dependent fluorescent "on-off" determination of $\mathrm{NO}_{2}{ }^{-}$and $\mathrm{CN}^{-}$ions in water samples [141]. In which, at pH 5.0 and 8.0, the probe approximately quantify the $\mathrm{NO}_{2}{ }^{-}$and $\mathrm{CN}^{-}$ions with limits of $5 \mu \mathrm{M}$ and $5 \mathrm{nM}$, respectively. In contrast to other anion sensor reports by $\mathrm{Cu}$ NCs, Prof. Huang's research group developed the trypsin-stabilized Cu NCs $(\Phi=1.1 \%)$ towards the "turn-on" detection of pyrophosphate (PPi) with an 
LOD of $101 \mathrm{nM}$ [142]. Moreover, this probe also achieved good linear relationship between the PPi concentration range of $78 \mu \mathrm{M}-20 \mathrm{mM}$.

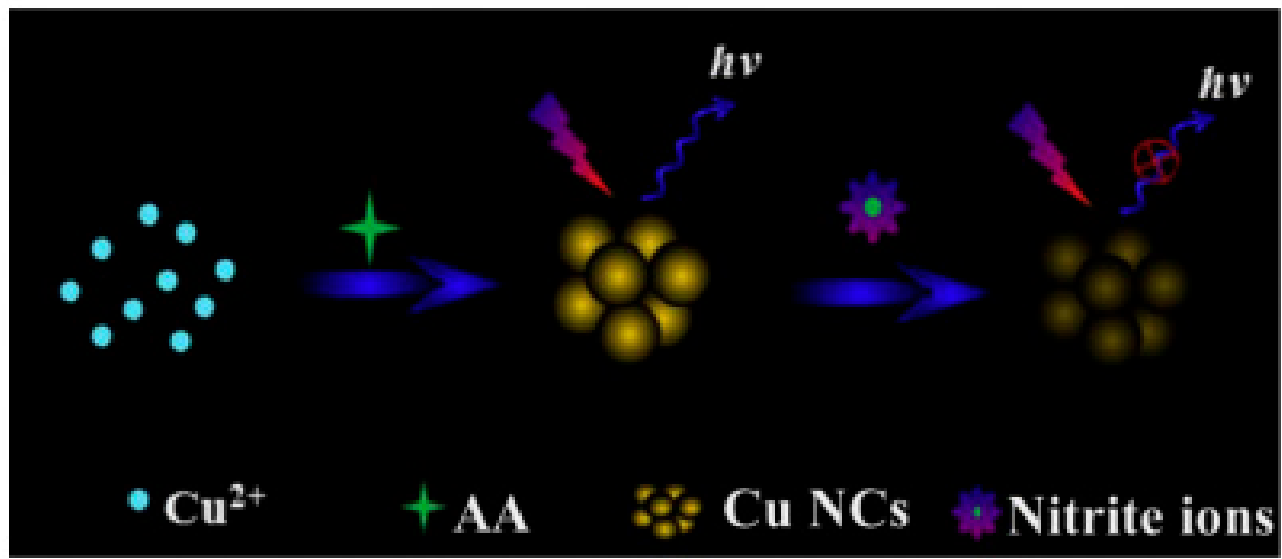

Figure 11. Schematic diagram of the mechanism of the detection of nitrite ions by the FL Cu NCs (Copyright Ref [139], Elsevier publications).

Similar to metal ions and anions sensors, scaffold-stabilized $\mathrm{Cu}$ NCs were also efficiently utilized in the detection of biomolecules, such as biothiols, cysteine, and glucose. For example, Hu et al. presented the DNA-Cu NCs based recognition of biothiols, such as GSH, Cys, and homocysteine (Hcy) via fluorescent-quenching responses [143] with affordable ranges and limits. Notably, this work was also applied in plasma samples. On the other hand, BSA-templated $\mathrm{Cu}$ NCs were used as peroxidase mimetics for the identification of $\mathrm{H}_{2} \mathrm{O}_{2}$ and glucose [144]. As shown in Figure 12, the addition of $2 \mathrm{mM}$ glucose resulted in a bluer color than that of $5 \mathrm{mM}$ fructose, lactose, or maltose.

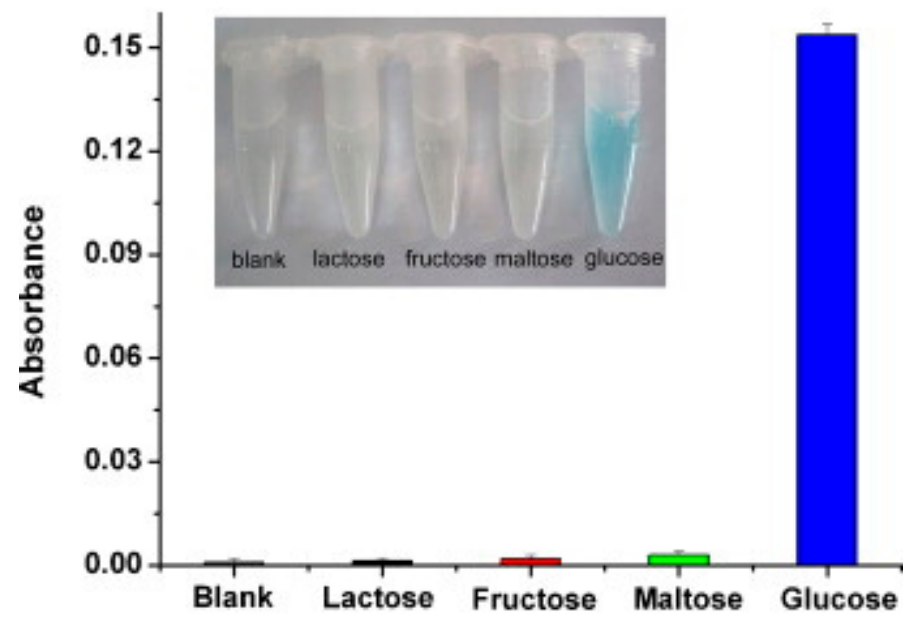

Figure 12. Determination of the selectivity of glucose detection with $5 \mathrm{mM}$ lactose, $5 \mathrm{mM}$ fructose, $5 \mathrm{mM}$ maltose, and $2 \mathrm{mM}$ glucose. The error bars represent the standard deviation of three measurements. Inset: the color change with the different solutions (Copyright Ref [144], ELSEVIER publications).

Added to this research, a guanosine $5^{\prime}$-triphosphate (GTP) sensor has been delivered by using histidine-protected $\mathrm{Cu}$ NCs with a quantum yield of 1.6\% [145]. Zhao et al. presented an impressive work for the detection of GTP by fluorescence quenching response. However, other nucleoside triphosphates including adenosine-5' $5^{\prime}$-triphosphate (ATP), CTP, UTP, and other inorganic anions, such as $\mathrm{P}_{2} \mathrm{O}_{7}{ }^{4-}, \mathrm{PO}_{4}{ }^{3-}$, and $\mathrm{CH}_{3} \mathrm{COO}^{-}$, have no such effect on $\mathrm{Cu}$ NC emission. By contrast, Wang and co-workers accounted the DNA-templated $\mathrm{Cu}$ NCs in lieu of the assay of ATP via target-induced 
structure-switching design [146]. This assay method showed an exciting fluorescence "turn-on" response compared with that of other non-specific nucleosides, such as CTP, UTP, and GTP. Moreover, this probe witnessed a dynamic assay range from $0.01 \mathrm{nM}$ to $100 \mathrm{nM}$ with an LOD of $5 \mathrm{pM}$.

In biomolecule detection, the lysozyme functionalized fluorescent copper nanoclusters (Lys-Cu NCs; $\Phi=5.6 \%$ )-based glucose sensor viaa fluorescence quenching effect was reported by Wang et al. [147]. Lys-Cu NCs displayed the two linear response ranges with glucose between 0.03-10 $\mu \mathrm{M}$ and 0.5-10 mM with an LOD of $1.9 \mathrm{nM}$. In this course, fluorimetric sensing of Cys through the formation of various copper nanoclusters (Cys-Cu NCs) with different sizes were described [148]. As shown in Figure 13, in contrast to other amino acids, addition of $\mathrm{Cu}^{2+}$ to Cys solution leads to production of Cys-Cu NCs, and the fluorescence intensity increased with the accumulation of cysteine from $5 \mu \mathrm{M}$ to $50 \mu \mathrm{M}$. In the presence of various concentrations of $\mathrm{Cys}$, two linear ranges were observed between $5 \mu \mathrm{M}$ to $50 \mu \mathrm{M}$ and $60 \mu \mathrm{M}$ to $500 \mu \mathrm{M}$ with LOD values of $2.4 \mu \mathrm{M}$ and $55 \mu \mathrm{M}$, separately.

The sensory studies of templated $\mathrm{Cu}$ NCs have been extended to detection of glycoproteins as noted next. For instance, BSA-Cu NCs were further functionalized by 3-aminophenylboronic acid and consumed in the sensitive detection of glycoproteins [149] via a fluorescence quenching response. The probe APBA-Cu NCs displayed a wide linear range of 5-220 nM and an LOD of 2.6 nM. Moreover, $\mathrm{Li}$ et al. successfully exploited this method for the determination of glycoproteins in the egg white of chickens and human urine samples, which shows quantitative spike recoveries from $95 \%$ to $104 \%$. Zhao and co-workers described 4-methylthiolphenol functionalized $\mathrm{Cu} \mathrm{NCs}$ with a quantum yield of $2.4 \%$ in ethanol as an aggregation-induced emission probe and also consumed in $\beta$-galactosidase activity assay [150] by fluorescence "turn-off" response.



Figure 13. The effect of different amino acids on copper sulfate solution $(\mathrm{pH}=12)$. From left to right: with Cys, Val, Gln, Ala, Lys, Met, Glu, Thr, Asn, Asp, Gly, Ser, Leu, Pro, Ile, Phe, Arg, Tyr, His, Trp, respectively (Copyright Ref [148], Springer publications).

Related to the nanoclusters of $\mathrm{Au}$ and $\mathrm{Ag}, \mathrm{Cu} \mathrm{NCs}$ with double-strand DNA (dsDNA) scaffold were also used in the recognition of microRNAs as defined next. Wang et al. presented DNA-Cu NCs for the quantitative detection of microRNAs via emission "turn-off" response [151]. Further, this work demonstrated the linear range from $1 \mathrm{pM}$ to $10 \mathrm{nM}$ with an LOD of 1 pM. By contrast, Prof. Hosseini described the DNA-Cu NC-based "turn-on" recognition of microRNA-155 [152]. In which, DNA-Cu NCs witnessed linear fluorescent enhancement towards miRNA-155 between $50 \mathrm{pM}$ to $10 \mathrm{nM}$, with an LOD value of $11 \mathrm{pM}$. This method was also applied in human plasma and saliva.

Next, $\mathrm{Cu}$ NCs were meritoriously applied in bio-imaging studies as noted below. In this study, artificial peptide CLEDNN-templated $\mathrm{Cu}$ NCs with $\Phi=7.3 \%$ were used in bio-imaging and temperature-sensing applications by Huang et al. [153]. Basu and co-workers also presented GSH-stabilized multi-color emissive Cu NCs ( $\Phi=0.438-1.27 \%)$ for bio-imaging investigations [154]. Here, copper nanoclusters countersigned with four different color emissions, such as blue, cyan, green, and orange-red, in water, which displayed low toxicity with imaging in OAW42 cell lines. Notably, $\mathrm{Cu}$ NCs were also used as $\mathrm{pH}$ sensors as in the case of other nanoclusters. For example, 
Wang et al. described the trypsin-stabilized fluorescent $\mathrm{Cu}$ NCs $(\Phi=1.1 \%)$ as a reversible $\mathrm{pH}$ sensor [155] between $\mathrm{pH}$ values 2.02-12.14. In this work, the $\mathrm{Cu}$ NCs form a blue precipitate in alkaline medium, which is restored upon dissolution in acid medium. Similar to the above report, Zhang et al. attested the reversible fluorescent $\mathrm{pH}$-sensing ability of natural silk fibroin-capped Cu NCs (SF@Cu NCs) [156]. The author applied this method in water samples and demonstrated its potential practical application.

In addition to various sensor interrogations, $\mathrm{Cu}$ NCs were found to have potential in the detection of explosive materials. Prof. Wu's research paper indicated explosive determination by using BSA-Cu NCs [157]. The probe determined the 2,4,6-trinitrophenol via fluorescent "turn-off" and had linearity between $0.8 \mu \mathrm{mol} \cdot \mathrm{L}^{-1}$ to $100 \mu \mathrm{mol} \cdot \mathrm{L}^{-1}$ with an LOD of $20 \mathrm{nmol} \cdot \mathrm{L}^{-1}$. In this method, Rogach and co-workers established the sensor efficacy of GSH-Cu NC incorporation in metal-organic frameworks (ZIF-8) towards the recognition of 2,4,6-trinitrotoluene by emission quenching [158]. Interestingly, $\mathrm{Cu} \mathrm{NCs}$ were reported as probes for the identification of water in organic solvents at ultralow level (ppm) [159]. Moreover, the aggregation-induced emission enhancement capability of $\mathrm{Cu}$ NCs may lead to various future sensor applications [160].

\section{Pt NCs in Sensory and Bio-Imaging Studies}

Given the importance of nanocluster-based fluorescent sensors, fluorescent Pt NCs were developed, and currently, many research discoveries are being reported. Previously, Prof. Zhang proposed that a nonmetallic platinum nanocluster was responsible for the observed fluorescence behavior [161]. However, the fluorescent property of Pt NCs was found to be responsible for its sensor interrogations. For example, George and co-workers reported the utilization of dimethylformamide-protected Pt NCs as a fluorescent sensor towards Fe(III) ions in aqueous medium [162]. The probe displayed fluorescent "turn-off" selectivity to Fe(III) ions with impressive human blood sample analysis. In contrast to metal ion sensor, BSA-Pt NCs were used in the hypochlorite assay by fluorescent quenching [163] and oxidation mechanism. Given the negligible effect of other interferences, this method was validated as highly selective.

In the detection of biologically important species, Jin and Shang co-workers represented the ultra-small Pt NCs $(\Phi=8.4 \%)$ as robust peroxidase mimics for colorimetric recognition of glucose in human serum [164]. This work revealed the Stern-Volmer plot with good linear relationship from $0 \mu \mathrm{M}$ to $200 \mu \mathrm{M}$ with an LOD of $0.28 \mu \mathrm{M}$. Moreover, upon addition of glucose, the blue color was visualized more than that of other carbohydrates (lactose, fructose, sucrose, and maltose) at higher concentration. $\mathrm{Xu}$ et al. described the hydrothermal synthesis of highly luminescent polyethylenimine-protected Pt NCs (Pt NCs@PEI; $\Phi=28 \%$ ) and applied it in the recognition of nitroimidazoles [165]. Pt NCs@PEI effectively determined trace amount of metronidazole (MTZ), used in treating parasitic infections, at a linear response between $0.25 \mu \mathrm{M}$ to $300 \mu \mathrm{M}$ with an LOD of $0.1 \mu \mathrm{M}$.

$\mathrm{Pt}$ NCs have also been used considerably in cellular imaging practices. For instance, Chen and co-workers validated Pt NC-based bio-imaging and photothermal treatment $[166,167]$. They united the spontaneous intracellular creation of fluorescent Pt NCs with a photothermal treatment of tumors through water-soluble porphyrin tetrakis(sulfonatophenyl)porphyrin, leading to synergistic effects and enhancement of the therapeutic efficacy of IR irradiation [167], as illustrated in Figure 14. 


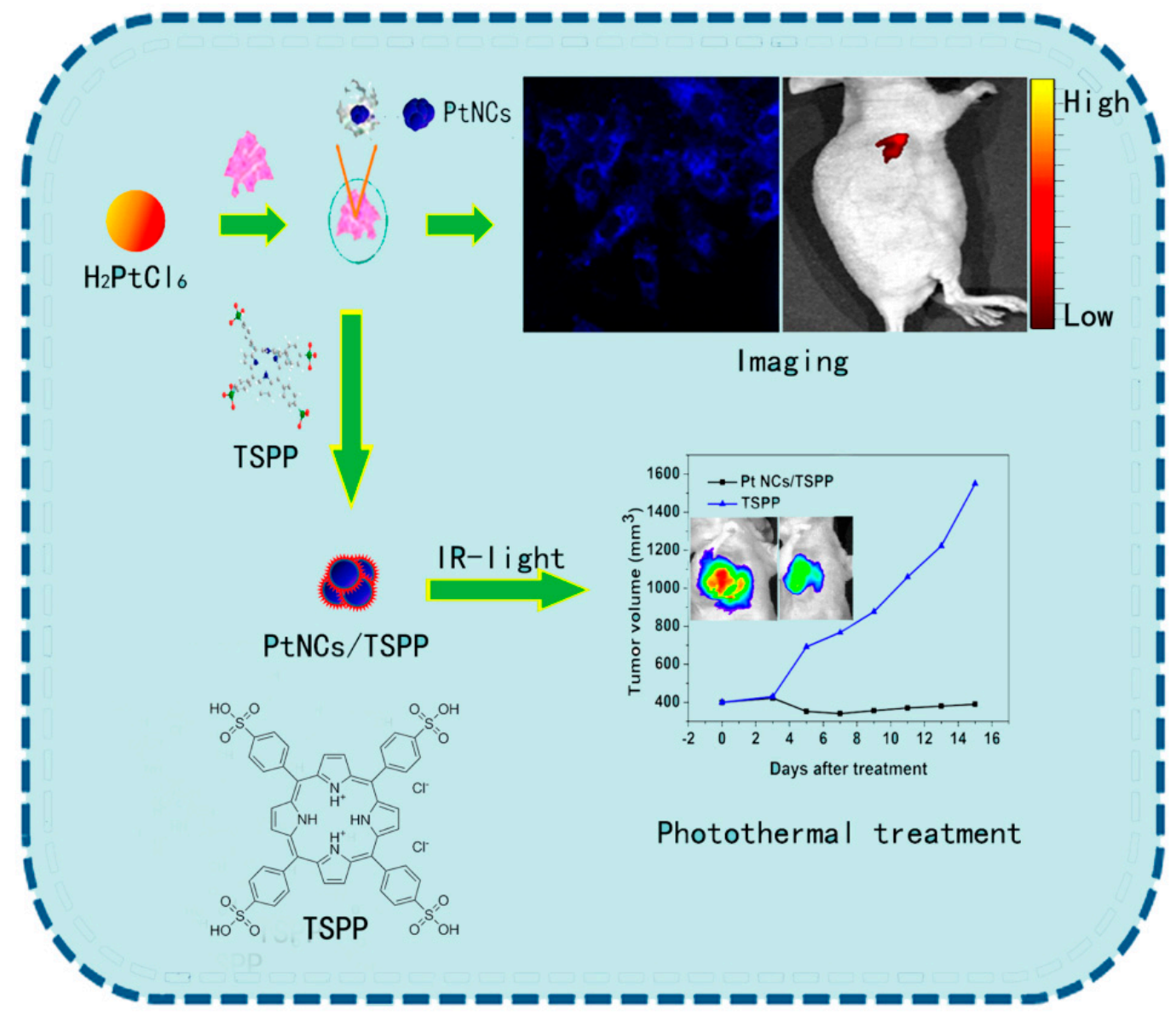

Figure 14. Schematic illustration of the study rationale and design (Copyright Ref [167], American Chemical Society).

\section{Other Metal Nanoclusters as Sensors}

The nanoclusters of $\mathrm{Au}, \mathrm{Ag}, \mathrm{Cu}, \mathrm{Pt}$, and currently other metal nanocluster-based sensory are becoming interesting topics. Very excitingly, those M-NCs may also be applied in sensory and imaging studies as noted subsequently. In this direction, King et al. pronounced the plasmonic colorimetric sensor ability of aluminum nanoclusters (Al NCs) [168], which may lead to the development of Al NC-based sensors for visual readout of a variety of analytes. As an addition to this research, palladium nanoclusters (Pd NCs) were established by Prof. Atta in the past decade [169]. Pd NC-coated polyfuran was used as a sensor probe for the determination of catecholamine neurotransmitters and paracetamol. However, this work applied electrochemical investigations not fluorescent studies, and hence, cannot be attested to our current focus. The uses of metal nanoclusters of $\mathrm{Cd}$ and $\mathrm{Ir}$ were also validated in cellular imaging studies $[170,171]$. Sarparast et al. represented such Cd NCs in a protein matrix, which were applied in targeted drug delivery and cellular imaging [170]. In a similar fashion, Vankayala and co-workers recognized the cellular imaging practice of highly fluorescent and biocompatible Ir NCs with a quantum yield of $0.36 \%$ [171]. Notably, the development of fluorescent nanoclusters, other than $\mathrm{Au}, \mathrm{Ag}, \mathrm{Cu}$, and $\mathrm{Pt}$ still requires more focus to improve their practicability. Hence, many scientists are working on these research investigations.

\section{Bi-Metallic Nanoclusters in Sensors and Bio-Imaging}

Given the improved stability and optical properties, research on bi-metallic NCs have gained increasing attention. Notably, many reports on bi-metallic NCs are still more operative towards sensory, bio-imaging and drug delivery. Therefore, in this section, we intend to deliver a few examples of 
sensory and bio-imaging applications of bi-metallic NCs. In the last decade, Su et al. conveyed the sensor utility of DNA-templated copper/silver nanoclusters (DNA-Cu/Ag NCs) in the presence of mercaptopropionic acid (MPA) for the determination of $\mathrm{Cu}^{2+}$ ions via fluorescence recovery [172]. Here, in the presence of MPA, the fluorescence of DNA-Cu/Ag NCs was quenched and then recovered during the addition of $\mathrm{Cu}^{2+}$ ions. The linear concentration range of $\mathrm{Cu}^{2+}$ ions was established as $0-0.2 \mu \mathrm{M}$ with an LOD of $2.7 \mathrm{nM}$. Next, mercaptosuccinic acid-stabilized AgAu alloy nanoclusters (MSA-AgAu NCs) with highly red fluorescence were developed by Prof. Chen's research group and applied in the fluorescence-enhanced detection of $\mathrm{Al}^{3+}$ ions [173]. In this work, the linear $\mathrm{Al}^{3+}$ concentration lies between $2.0-30 \mu \mathrm{M}$ with an LOD of $0.8 \mu \mathrm{M}$.

As mentioned earlier, the templated $\mathrm{Ag} / \mathrm{Au}$ NCs became more attractive by tuning the atomic ratio. Moreover, among other bi-metallic systems, the $\mathrm{Ag} / \mathrm{Au}$ system provides more stability with enhanced fluorescence and biocompatibility for sensory and imaging studies. Some metal ion sensor-based Ag/Au bi metallic NCs are as follows. Zhang et al. established the Au/Ag NCs in the protein matrix with "Silver Effect"-enhanced red fluorescence [174]. Importantly, the above-mentioned probe $\mathrm{Au}-\mathrm{Ag} \mathrm{NCs}$ facilitated the recognition of $\mathrm{Hg}^{2+}$ and $\mathrm{Cu}^{2+}$ ions with corresponding LODs of 0.30 and $0.60 \mathrm{nM}$ in blood samples. Continuing, Zheng and co-workers described the (BSA)-stabilized yellow emissive AuAg bimetallic nanoclusters as a sensory probe for $\mathrm{Hg}^{2+}$ ions by "turn-off" response [175]. The linear detection concentration of $\mathrm{Hg}^{2+}$ ions was established as $50 \mathrm{nM}$ to $63 \mu \mathrm{M}$ with an LOD value of $13 \mathrm{nM}$. In this way, lipoic acid-protected red emissive Au/ Ag nanoclusters with a quantum yield of $6.4 \%$ were applied as a probe for the determination of $\mathrm{Fe}^{3+}$ ions and temperature through fluorescence quenching [176]. The above probe was developed by Prof. Wang's research unit via one-step green synthesis and has linear reversible response to temperatures between $20^{\circ} \mathrm{C}$ and $65^{\circ} \mathrm{C}$. Furthermore, linear fluorescent-quenching responses of $\mathrm{Au} / \mathrm{Ag}$ nanoclusters with $\mathrm{Fe}^{3+}$ ions were observed between $1-80 \mu \mathrm{M}$ with an LOD value of $0.5 \mu \mathrm{M}$. The sensor ability of the probe was also validated through cellular imaging studies.

$\mathrm{AuAg}$ NCs with diverse templates were also reported for the detection of different metal ions as noted next. Yang et al. described the 11-mercaptoundecanoic acid (11-MUA)-capped AuAg NCs, which show significant fluorescence quenching in the presence of $\mathrm{Cr}(\mathrm{III})$ ions [177]. However, the probe participated in the redox reaction (between $\mathrm{Cr}(\mathrm{VI})$ and $\mathrm{AA}$ ) for indirect discovery of $\mathrm{Cr}(\mathrm{VI})$ ions. The above interrogation estimated the linear ranges of $\mathrm{Cr}(\mathrm{III})$ and $\mathrm{Cr}(\mathrm{VI})$ as $0.08 \mu \mathrm{M}$ to $6 \mu \mathrm{M}$ and $0.6 \mu \mathrm{M}$ to $10 \mu \mathrm{M}$, respectively, with matching LOD values of 0.05 and $0.3 \mu \mathrm{M}$. In a similar trend, DNA-scaffiolded $\mathrm{Ag}-\mathrm{Au} \mathrm{NCs}$ were expended in the selective recognition of $\mathrm{Hg}^{2+}$ ions through fluorescence quenching [178]. Similar to Ag-Au NCs, other bi-metallic NCs were also consumed in analyte detection. Ding et al. presented dual-emitting BSA-Pt-Au NCs in the detection of mercury ions and cysteine via ratiometric fluorescence responses [179]. In this result, upon addition of metal ions, the BSA-Pt-Au NCs exhibited emission quenching and then recovered in the presence of Cys. The linear concentration range of $\mathrm{Hg}^{2+}$ and Cys was observed between $0.5 \mathrm{nM}$ to $22 \mu \mathrm{M}$ and $0.1 \mu \mathrm{M}$ to $50 \mu \mathrm{M}$ with LODs of $0.3 \mathrm{nM}$ and $0.04 \mu \mathrm{M}$, respectively. Wang and co-workers described the fluorometric determination of $\mathrm{Cd}$ (II) and $\mathrm{Hg}$ (II) ions by using gold-nickel bi-metallic NCs [180]. The fluorescence signal was strongly enhanced in the presence of $\mathrm{Cd}$ (II) ions but quenched upon addition of $\mathrm{Hg}$ (II) ions via a diverse electron transfer mechanism (Figure 15). This probe witnessed a good linear relationship with Cd(II) ions from $0.005 \mu \mathrm{M}$ to $100 \mu \mathrm{M}$ with an LOD of $1.75 \mathrm{nM}$. On the other hand, the linear relationship for $\mathrm{Hg}$ (II) ions was appraised as $0.005-1.0 \mu \mathrm{M}$ with an LOD value of $1.70 \mathrm{nM}$. Moreover, the above work was also authenticated by serum sample analysis. 


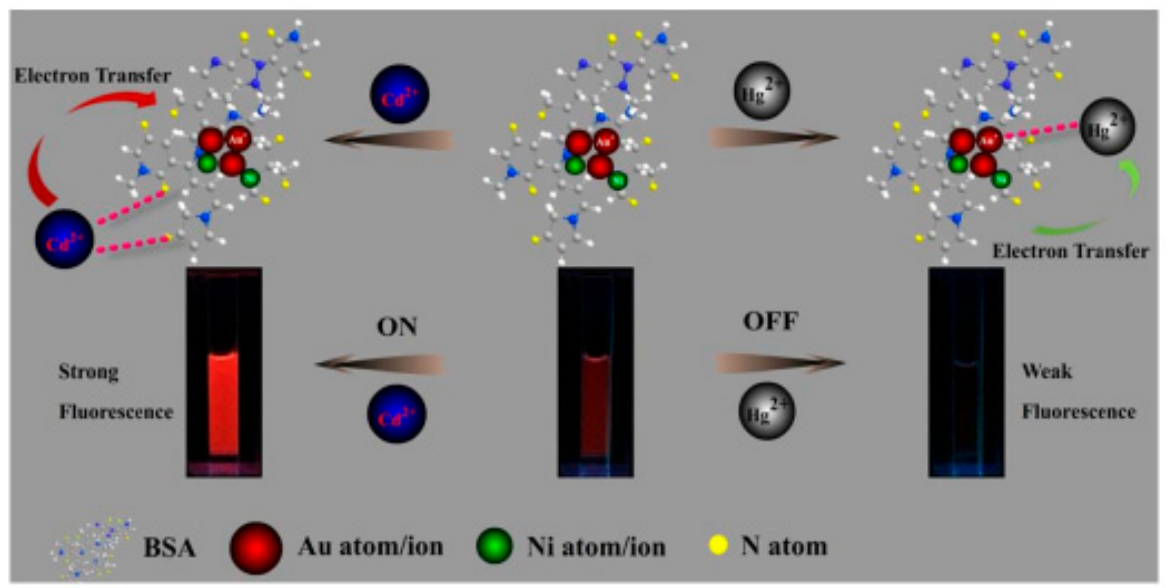

Figure 15. Schematic diagram of the mechanism of the detection of $\mathrm{Cd}^{2+}$ and $\mathrm{Hg}^{2+}$ ions by the fluorescent BSA-Au-Ni NCs (Copyright Ref [180], Springer publications).

Comparable with the detection of metal ions, bi-metallic NCs were also used in the selective acknowledgement of anions as revealed successively. Prof. Chang's research study exposed the effective utility of DNA-templated gold/silver nanoclusters $(\Phi=3.9 \%)$ in the assay of $\mathrm{S}^{2-}$ ions [181] with an LOD of $0.83 \mathrm{nM}$ via fluorescent "turn-off" response. In a related fluorescence response, the detection of hypochlorite in tap water was exposed by BSA-stabilized Au-Ag NCs $(\Phi=18.6 \%)$ [182], in which the linearly correlated hypochlorite concentration ranged from $0.7 \mu \mathrm{M}$ to $15 \mu \mathrm{M}$ with an LOD of $80 \mathrm{nM}$. A similar probe (BSA-Au-Ag NCs) was also used by Zhou et al. for the highly sensitive recognition of inorganic pyrophosphatase activity with the help of copper ion $\left(\mathrm{Cu}^{2+}\right)$ and inorganic pyrophosphate ion (PPi), as illustrated in Figure 16 [183].

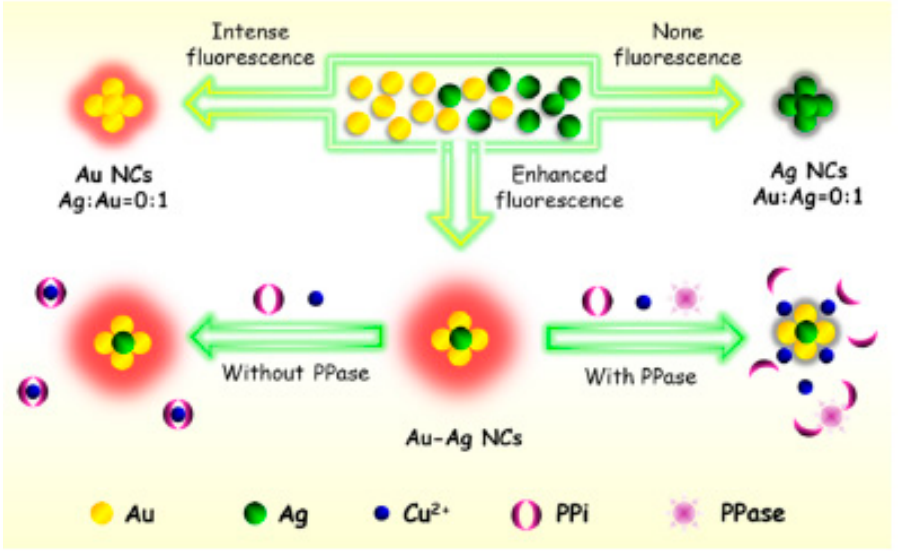

Figure 16. Schematic illustration of gold-silver bimetallic nanocluster (Au-Ag NCs) based fluorescent probes for quantitative monitoring of inorganic pyrophosphatase (PPase) activity coupling enzyme-induced hydrolysis of pyrophosphate ion $\left(\mathrm{PPi}, \mathrm{P}_{2} \mathrm{O}_{7}{ }^{4-}\right)$ with the release of copper ion $\left(\mathrm{Cu}^{2+}\right)$ from the $\mathrm{Cu}^{2+}$-PPi complexes (Copyright Ref [183], American Chemical Society).

$\mathrm{Li}$ et al. approved the sensor ability of DNA-capped $\mathrm{Au} / \mathrm{Ag} \mathrm{NCs}$ in the fluorometric and colorimetric determination of $\mathrm{I}^{-}$ions by fluorescence quenching [184]. Here, the probe showed a good linear range from $0 \mu \mathrm{mol} \cdot \mathrm{L}^{-1}$ to $10 \mu \mathrm{mol} \cdot \mathrm{L}^{-1}$ for iodide ions with an LOD of $0.3 \mu \mathrm{mol} \cdot \mathrm{L}^{-1}$. Alternatively, Ding et al. applied the DNA-templated copper/silver nanoclusters (DNA-Cu/AgNCs) for selective sensing of $\mathrm{S}^{2-}$ ions via emission quenching [185]. DNA-Cu/AgNCs displayed a linear detection range of $\mathrm{S}^{2-}$ between $10 \mathrm{pM}$ to $1 \mathrm{mM}$ with an LOD of $3.75 \mathrm{pM}$. Moreover, it was successfully applied in the detection of $\mathrm{H}_{2} \mathrm{~S}$ in poisoning blood. 
Given the importance of biomolecule determination, bi-metallic NCs were also consumed for their fluorescent sensor recognition as subsequently defined. For instance, Wang et al. reported the detection of biologically important thiols, such as Cys and GSH via fluorescence quenching of BSA-Au/Ag NCs [186]. Under optimized conditions, the above probe has excellent linear fluorescence quenching in the presence of Cys $(20 \mathrm{nM}-80 \mu \mathrm{M}$, LOD: $5.87 \mathrm{nM})$ and GSH (2-70 $\mu \mathrm{M}, \mathrm{LOD}: 1.01 \mu \mathrm{M})$. By contrast, fluorescence turn-on selective identification of His and Cys were discovered by Sun and co-workers using 11-mercaptoundecanoic acid (11-MUA) protected Ag/ Au bimetallic nanoclusters $\left(\Phi=4.2 \%\right.$ ) combined with $\mathrm{Cu}^{2+}$ ions [187]. The probe can detect His and Cys within the linear concentration range of $0.25-9 \mu \mathrm{M}$ and $0.25-7 \mu \mathrm{M}$ with LODs of $87 \mathrm{nM}$ and $111 \mathrm{nM}$, correspondingly.

Prof. Wu's research legitimated the fabrication of gold-platinum bimetallic nanoclusters (Au-Pt NCs) with variable $\mathrm{Au} / \mathrm{Pt}$ molar ratios via a one-pot synthetic route and applied in colorimetric acknowledgement of glucose [188]. Here, Au-Pt NCs led to a glucose oxidase cascade-catalyzed system using 3,3',5,5'-tetramethylbenzidine as a chromogenic substrate. This convenient naked eye quantification has linear responses between $5 \mu \mathrm{M}$ to $55 \mu \mathrm{M}$ with an LOD value of $2.4 \mu \mathrm{M}$. Moreover, upon incremental addition of glucose, the absorption spectra seem to be enhanced at $652 \mathrm{~nm}$ along with blue color visualization by the naked eye (Figure 17).
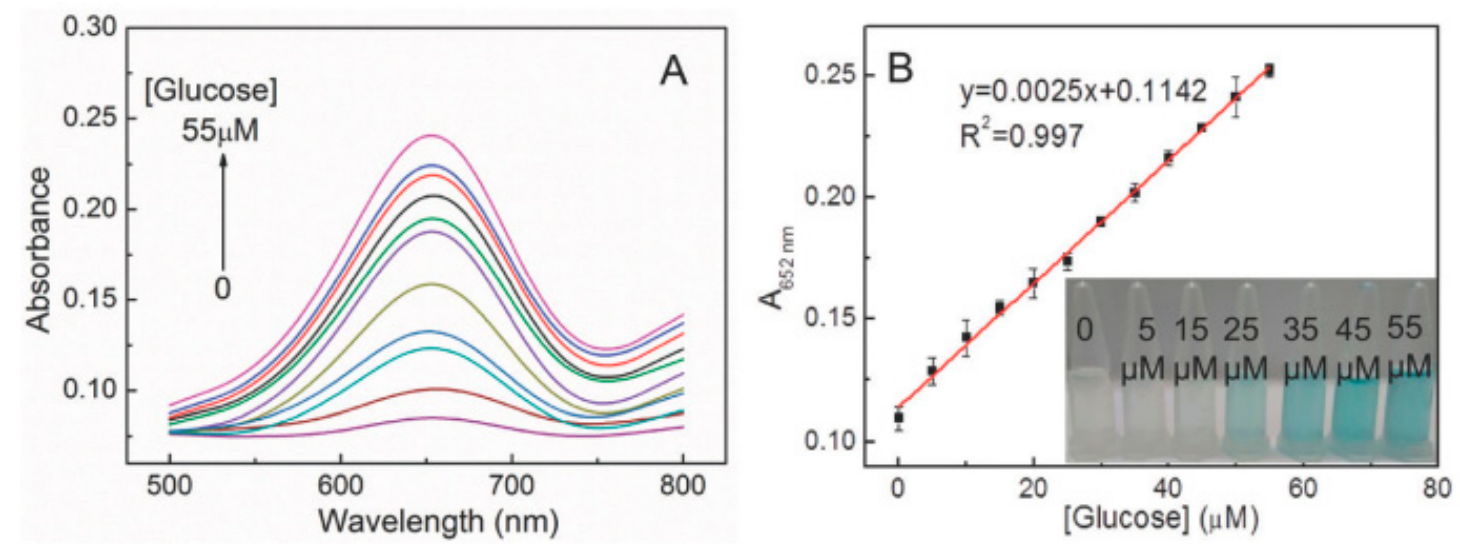

Figure 17. (A) Absorption spectra of the Au-Pt NCs-GOx-TMB system in the presence of different glucose concentrations $(0,5,10,15,20,25,30,35,40,45,50$, and $55 \mu \mathrm{M})$. (B) Linear calibration curve of the absorbance at $652 \mathrm{~nm}$ against glucose concentration. The inset shows the corresponding photographs for different concentrations of glucose (Copyright Ref [188], Royal Society of Chemistry).

Ahn et al. presented the detection of adenosine by consuming DNA-templated Cu/Ag NCs and using the s-adenosylhomocysteine hydrolase method [189]. The adenosine was detected between 0 and $1 \mu \mathrm{M}$ with an LOD of $19 \mathrm{nM}$ more than that of other analogs, such as AMP, ADP, ATP, cAMP, guanosine, cytidine, and urine. Moreover, this method was also well verified with real human serum sample studies. In addition to this research, Li et al. marked the cost-effective highly sensitive fluorometric assay of acetylcholinesterase (AChE-significant neural enzyme), which can specifically catalyze the hydrolysis of acetylcholine (Ach-a central neurotransmitter), to acetic acid and choline [190]. Similar to individual M-NCs, hybrid bi-metallic NCs were also used in cellular imaging investigations as follows.

Previously, $\mathrm{Hu}$ et al. reported the hybrid ultra-small Au/Gd-NCs in triple-modal NIRF/CT/MRI imaging [191]. This work demonstrates the penetration of Au/Gd NCs into a solid tumor without any toxicity in vivo. In a similar fashion, BSA-stabilized Au-Ag NCs $(\Phi=11.7 \%)$ were established for the delivery of the therapeutic suicide gene in HeLa cancer cells by Dutta and co-workers [192]. The above study described the mechanism of uptake and manner of cell death and revealed its future applicability. In this trend, bright fluorescent cytidine-mediated Au-Ag NCs were developed by Chen et al. and utilized for both in vitro cellular imaging and tumor in vivo detection [193]. The synthesis and tumor detective application of the above-acknowledged probe is shown in Figure 18. 


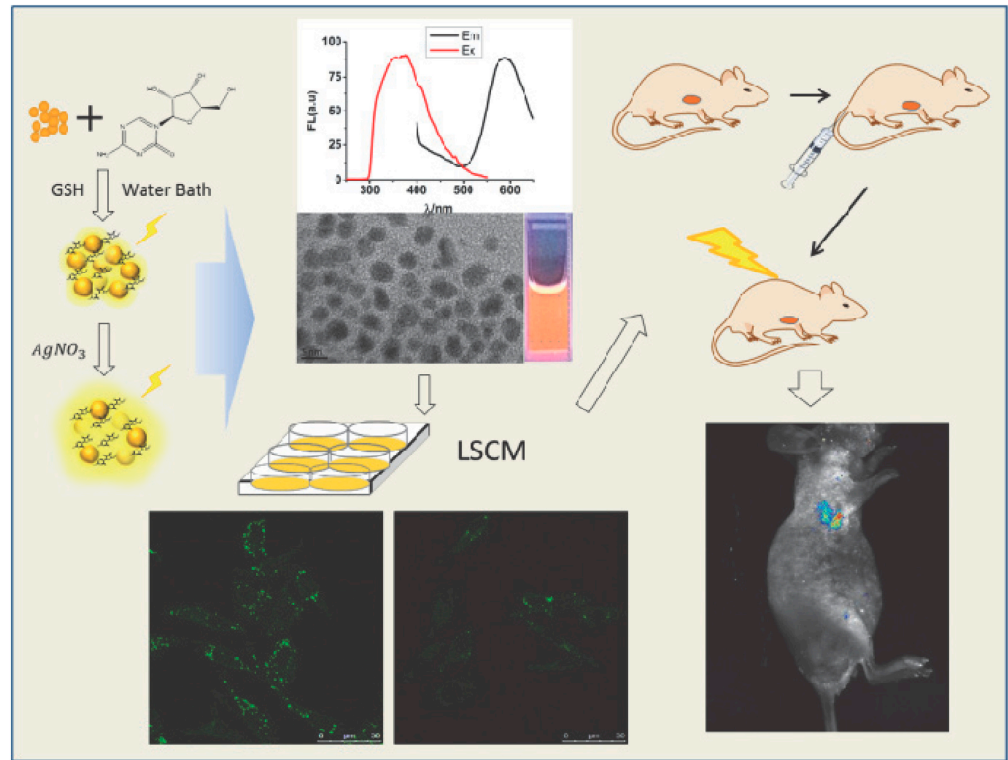

Figure 18. Scheme illustration of the process for cytidine mediated gold-silver nanoclusters (AuAg NCs) (Copyright Ref [193], WILEY publications).

As in the case of other individual NCs, bi-metallic NCs were used in $\mathrm{pH}$ and temperature sensor applications. For example, Prof. Chang's research paper defined the $\mathrm{pH}$ sensing ability of AuCu bimetallic NCs $(\Phi=4.8 \%)$, which was synthesized through a one-pot approach [194]. Notably, the above probe also showed the catalytic activity in the degradation of methylene blue. Han et al. represented the temperature-sensing capability of $\mathrm{Cu} / \mathrm{Ag}$ NCs obtained from weakly luminescent glutathione (GSH)-capped $\mathrm{Cu}$ NCs [195]. Cu/Ag NCs witnessed fluorescence quenching between $4{ }^{\circ} \mathrm{C}$ and $55^{\circ} \mathrm{C}$. Further to note, the aggregation-induced behavior of M-NCs and bi-MNCs were evaluated and may be applied in many biological applications in the near future [196]. Attracted by the effective applications of M-NCs and bi-MNCs, researchers currently intend to develop luminescent tri-metallic NCs with high quantum yields [197].

\section{Advantages and Limitations}

NC-based sensory investigations have several advantages and a few limitations as indicated below.

1. In contrast to plasmonic nanoparticles, M-NCs have an ultra-small size with ultimate fluorescence. Hence, they can be used as fluorescent "Off" or "On" probes in a variety of analytical studies.

2. Contrary to fluorescent quantum dots, the optical properties of M-NCs can be enhanced by controlling the surface functionalization, which also leads to NCs with diverse emissive colors.

3. M-NCs can be synthesized via a one-pot synthesis compared with the complicated synthesis of organic sensory probes.

4. Luminescent M-NCs exhibit less toxicity and good biocompatibility compared with fluorescent quantum dots and organic fluorophores. Hence, they can be used in biological applications, such as imaging and drug delivery studies.

5. The emissive characteristics of M-NCs are limited to the ligands functionalized on the surface and to stability with respect to temperature, time, and $\mathrm{pH}$ values.

6. The optical properties are also limited to overall uniform cluster particle sizes. Similar functional groups on the NC surface with diverse particle sizes may also possibly emit different colors. Therefore, maintenance of the experimental procedure is highly essential to obtain reproducible results. 


\section{Conclusions and Perspectives}

In this review, we have summarized the recent progress in chemosensory applications of luminescent metal NCs with particular focus on $\mathrm{Au}, \mathrm{Ag}, \mathrm{Cu}, \mathrm{Pt}$, and their alloy clusters. These NCs remain more attractive due to their diverse color emission properties by tuning the templates or metal ratios. Interestingly, they act as probes in specific analyte detection, such as metal ions, anions, biomolecules, peptides/proteins, and explosives. Moreover, due to their low toxicity and biocompatibility, they are also used in bio-imaging studies. Hence, in the presence of biofunctionalized scaffolds, the ultra-small metal NCs can be utilized in a variety of biomedical applications. The unique fluorescent property of those NCs enhances the reversible $\mathrm{pH}$ and temperature-sensing ability.

Although the M-NCs and bi-NCs have witnessed exciting progress, many limitations remain as a challenge.

1. The relation between structure and emission properties of many reported M-NCs remains insufficient. Hence, fundamental investigations on the structural properties of M-NCs need to be focused along with fluorescence studies.

2. Optimization of precursor/template concentration for stabilizing the M-NCs has been uncertain in many cases and must be clarified. Notably, in many reports, similar probes with various template or metal ion concentrations have been reported for diverse analyte detection. However, clear fundamental evidence to support their diverse optical properties has not been provided. This is an essential point to be addressed in future reports.

3. Mechanistic evidence for a few M-NC-based sensory reports remain inadequate. Hence, essential theoretical interrogations should be supplemented in the future.

4. NC-based based sensory applications by using optical devices have led them towards promising nanodevice-based commercial utilities.

5. Pt NCs based sensory research remains insufficient, with emitted fluorescence between $700 \mathrm{~nm}$ to $950 \mathrm{~nm}$ by utilization of diverse templates. Hence, much effort is needed to develop such probes for enhanced biological utilities.

6. The development of multifunctional M-NCs is helpful in biomedical diagnosis and treatment. Hence, considerable efforts are required to develop promising candidates.

Apart from the above-mentioned challenges, the research on M-NCs and bi-MNCs remains promising for sensory and biomedical applications. Further, many scientists continue to resolve many of the above issues, and hence, it is believed that NC-based sensory and theranostic applications should have a bright future.

Conflicts of Interest: The authors declare no conflict of interest.

\section{References}

1. Chakraborty, I.; Pradeep, T. Atomically Precise Clusters of Noble Metals: Emerging Link between Atoms and Nanoparticles. Chem. Rev. 2017, 117, 8208-8271. [CrossRef] [PubMed]

2. Song, X.-R.; Goswami, N.; Yang, H.-H.; Xie, J. Functionalization of metal nanoclusters for biomedical applications. Analyst 2016, 141, 3126-3140. [CrossRef] [PubMed]

3. Sun, H.-T.; Yoshio, S. Luminescent metal nanoclusters: Controlled synthesis and functional applications. Sci. Technol. Adv. Mater. 2014, 15, 014205. [CrossRef] [PubMed]

4. Zhao, T.; Zhou, T.; Yao, Q.; Hao, C.; Chen, X. Metal Nanoclusters: Applications in Environmental Monitoring and Cancer Therapy. J. Environ. Sci. Health C 2015, 33, 168-187. [CrossRef] [PubMed]

5. Santiago-Gonzalez, B.; Monguzzi, A.; Caputo, M.; Villa, C.; Prato, M.; Santambrogio, C.; Torrente, Y.; Meinardi, F.; Brovelli, S. Metal Nanoclusters with Synergistically Engineered Optical and Buffering Activity of Intracellular Reactive Oxygen Species by Compositional and Supramolecular Design. Sci. Rep. 2017, 7, 5976. [CrossRef] [PubMed] 
6. Tao, Y.; Li, M.; Ren, J.; Qu, X. Metal nanoclusters: Novel probes for diagnostic and therapeutic applications. Chem. Soc. Rev. 2015, 44, 8636-8663. [CrossRef] [PubMed]

7. Wilcoxon, J.P.; Abrams, B.L. Synthesis, structure and properties of metal nanoclusters. Chem. Soc. Rev. 2006, 35, 1162-1194. [CrossRef] [PubMed]

8. Yu, P.; Wen, X.; Toh, Y.-R.; Ma, X.; Tang, J. Fluorescent Metallic Nanoclusters: Electron Dynamics, Structure, and Applications. Part. Part. Syst. Charact. 2015, 32, 142-163. [CrossRef]

9. Zhang, L.; Wang, E. Metal nanoclusters: New fluorescent probes for sensors and bioimaging. Nano Today 2014, 9, 132-157. [CrossRef]

10. Lu, Y.; Chen, W. Sub-nanometre sized metal clusters: From synthetic challenges to the unique property discoveries. Chem. Soc. Rev. 2012, 41, 3594-3623. [CrossRef] [PubMed]

11. Fang, J.; Zhang, B.; Yao, Q.; Yang, Y.; Xie, J.; Yan, N. Recent advances in the synthesis and catalytic applications of ligand-protected, atomically precise metal nanoclusters. Coord. Chem. Rev. 2016, 322, 1-29. [CrossRef]

12. Li, J.; Zhu, J.-J.; Xu, K. Fluorescent metal nanoclusters: From synthesis to applications. TrAC Trends Anal. Chem. 2014, 58, 90-98. [CrossRef]

13. Li, C.; Chen, H.; Chen, B.; Zhao, G. Highly fluorescent gold nanoclusters stabilized by food proteins: From preparation to application in detection of food contaminants and bioactive nutrients. Crit. Rev. Food Sci. Nutr. 2016, 1-11. [CrossRef] [PubMed]

14. Li, M.; Gou, H.; Al-Ogaidi, I.; Wu, N. Nanostructured Sensors for Detection of Heavy Metals: A Review. ACS Sustain. Chem. Eng. 2013, 1, 713-723. [CrossRef]

15. Yuan, X.; Luo, Z.; Yu, Y.; Yao, Q.; Xie, J. Luminescent Noble Metal Nanoclusters as an Emerging Optical Probe for Sensor Development. Chem. Asian J. 2013, 8, 858-871. [CrossRef] [PubMed]

16. Chen, L.-Y.; Wang, C.-W.; Yuan, Z.; Chang, H.-T. Fluorescent Gold Nanoclusters: Recent Advances in Sensing and Imaging. Anal. Chem. 2015, 87, 216-229. [CrossRef] [PubMed]

17. Sun, J.; Jin, Y. Fluorescent Au nanoclusters: Recent progress and sensing applications. J. Mater. Chem. C 2014, 2, 8000-8011. [CrossRef]

18. Diez, I.; Ras, R.H.A. Fluorescent silver nanoclusters. Nanoscale 2011, 3, 1963-1970. [CrossRef] [PubMed]

19. Xu, H.; Suslick, K.S. Water-Soluble Fluorescent Silver Nanoclusters. Adv. Mater. 2010, 22, $1078-1082$. [CrossRef] [PubMed]

20. Lu, Y.; Wei, W.; Chen, W. Copper nanoclusters: Synthesis, characterization and properties. Chin. Sci. Bull. 2012, 57, 41-47. [CrossRef]

21. Wang, Z.; Chen, B.; Rogach, A.L. Synthesis, optical properties and applications of light-emitting copper nanoclusters. Nanoscale Horiz. 2017, 2, 135-146. [CrossRef]

22. Chakraborty, I.; Bhuin, R.G.; Bhat, S.; Pradeep, T. Blue emitting undecaplatinum clusters. Nanoscale 2014, 6, 8561-8564. [CrossRef] [PubMed]

23. Tanaka, S.-I.; Aoki, K.; Muratsugu, A.; Ishitobi, H.; Jin, T.; Inouye, Y. Synthesis of green-emitting Pt8 nanoclusters for biomedical imaging by pre-equilibrated Pt/PAMAM (G4-OH) and mild reduction. Opt. Mater. Express 2013, 3, 157-165. [CrossRef]

24. Sun, Y.; Wu, J.; Wang, C.; Zhao, Y.; Lin, Q. Tunable near-infrared fluorescent gold nanoclusters: Temperature sensor and targeted bioimaging. New J. Chem. 2017, 41, 5412-5419. [CrossRef]

25. Wang, Y.; Dai, C.; Yan, X.-P. Fabrication of folate bioconjugated near-infrared fluorescent silver nanoclusters for targeted in vitro and in vivo bioimaging. Chem. Commun. 2014, 50, 14341-14344. [CrossRef] [PubMed]

26. Wang, C.; Cheng, H.; Sun, Y.; Lin, Q.; Zhang, C. Rapid Sonochemical Synthesis of Luminescent and Paramagnetic Copper Nanoclusters for Bimodal Bioimaging. ChemNanoMat 2015, 1, 27-31. [CrossRef]

27. Tanaka, S.-I.; Miyazaki, J.; Tiwari, D.K.; Jin, T.; Inouye, Y. Fluorescent Platinum Nanoclusters: Synthesis, Purification, Characterization, and Application to Bioimaging. Angew. Chem. Int. Ed. 2011, 50, 431-435. [CrossRef] [PubMed]

28. Wang, Y.; Hu, L.; Li, L.; Zhu, J.-J. Fluorescent Gold Nanoclusters: Promising Fluorescent Probes for Sensors and Bioimaging. J. Anal. Test. 2017, 1, 13. [CrossRef]

29. Shang, L.; Dörlich, R.M.; Trouillet, V.; Bruns, M.; Ulrich Nienhaus, G. Ultrasmall fluorescent silver nanoclusters: Protein adsorption and its effects on cellular responses. Nano Res. 2012, 5, 531-542. [CrossRef] 
30. Jia, X.; Li, J.; Wang, E. Cu Nanoclusters with Aggregation Induced Emission Enhancement. Small 2013, 9, 3873-3879. [CrossRef] [PubMed]

31. Huang, X.; Ishitobi, H.; Inouye, Y. Formation of fluorescent platinum nanoclusters using hyper-branched polyethylenimine and their conjugation to antibodies for bio-imaging. RSC Adv. 2016, 6, 9709-9716. [CrossRef]

32. Shang, L.; Dong, S.; Nienhaus, G.U. Ultra-small fluorescent metal nanoclusters: Synthesis and biological applications. Nano Today 2011, 6, 401-418. [CrossRef]

33. Yuan, X.; Dou, X.; Zheng, K.; Xie, J. Recent Advances in the Synthesis and Applications of Ultrasmall Bimetallic Nanoclusters. Part. Part. Syst. Charact. 2015, 32, 613-629. [CrossRef]

34. Cercis, M.-B.; Francisco, H.; Cecilia, N. On the stability of noble-metal nanoclusters protected with thiolate ligands. Europhys. Lett. 2017, 119, 56002.

35. Huang, C.-C.; Yang, Z.; Lee, K.-H.; Chang, H.-T. Synthesis of Highly Fluorescent Gold Nanoparticles for Sensing Mercury(II). Angew. Chem. Int. Ed. 2007, 46, 6824-6828. [CrossRef] [PubMed]

36. Goswami, N.; Lin, F.; Liu, Y.; Leong, D.T.; Xie, J. Highly Luminescent Thiolated Gold Nanoclusters Impregnated in Nanogel. Chem. Mater. 2016, 28, 4009-4016. [CrossRef]

37. Aldeek, F.; Muhammed, M.A.H.; Palui, G.; Zhan, N.; Mattoussi, H. Growth of Highly Fluorescent Polyethylene Glycol- and Zwitterion-Functionalized Gold Nanoclusters. ACS Nano 2013, 7, 2509-2521. [CrossRef] [PubMed]

38. Deng, H.-H.; Shi, X.-Q.; Wang, F.-F.; Peng, H.-P.; Liu, A.-L.; Xia, X.-H.; Chen, W. Fabrication of Water-Soluble, Green-Emitting Gold Nanoclusters with a 65\% Photoluminescence Quantum Yield via Host-Guest Recognition. Chem. Mater. 2017, 29, 1362-1369. [CrossRef]

39. Muhammed, M.A.H.; Aldeek, F.; Palui, G.; Trapiella-Alfonso, L.; Mattoussi, H. Growth of In Situ Functionalized Luminescent Silver Nanoclusters by Direct Reduction and Size Focusing. ACS Nano 2012, 6, 8950-8961. [CrossRef] [PubMed]

40. Naaz, S.; Poddar, S.; Bayen, S.P.; Mondal, M.K.; Roy, D.; Mondal, S.K.; Chowdhury, P.; Saha, S.K. Tenfold enhancement of fluorescence quantum yield of water soluble silver nanoclusters for nano-molar level glucose sensing and precise determination of blood glucose level. Sens. Actuators B 2018, 255, 332-340. [CrossRef]

41. Ghosh, R.; Sahoo, A.K.; Ghosh, S.S.; Paul, A.; Chattopadhyay, A. Blue-Emitting Copper Nanoclusters Synthesized in the Presence of Lysozyme as Candidates for Cell Labeling. ACS Appl. Mater. Interfaces 2014, 6, 3822-3828. [CrossRef] [PubMed]

42. Wang, Z.; Chen, B.; Susha, A.S.; Wang, W.; Reckmeier, C.J.; Chen, R.; Zhong, H.; Rogach, A.L. All-Copper Nanocluster Based Down-Conversion White Light-Emitting Devices. Adv. Sci. 2016, 3, 1600182. [CrossRef] [PubMed]

43. Jenifer García, F.; Laura, T.-A.; José, M.C.-F.; Rosario, P.; Alfredo, S.-M. Aqueous synthesis of near-infrared highly fluorescent platinum nanoclusters. Nanotechnology 2015, 26, 215601. [CrossRef] [PubMed]

44. Jin, R. Atomically precise metal nanoclusters: Stable sizes and optical properties. Nanoscale 2015, 7, 1549-1565. [CrossRef] [PubMed]

45. Taylor, M.G.; Mpourmpakis, G. Thermodynamic stability of ligand-protected metal nanoclusters. Nat. Commun. 2017, 8, 15988. [CrossRef] [PubMed]

46. Goswami, N.; Luo, Z.; Yuan, X.; Leong, D.T.; Xie, J. Engineering gold-based radiosensitizers for cancer radiotherapy. Mater. Horiz. 2017, 4, 817-831. [CrossRef]

47. Yang, X.; Yang, L.; Dou, Y.; Zhu, S. Synthesis of highly fluorescent lysine-stabilized Au nanoclusters for sensitive and selective detection of $\mathrm{Cu}^{2+}$ ion. J. Mater. Chem. C 2013, 1, 6748-6751. [CrossRef]

48. Deng, H.-H.; Zhang, L.-N.; He, S.-B.; Liu, A.-L.; Li, G.-W.; Lin, X.-H.; Xia, X.-H.; Chen, W. Methionine-directed fabrication of gold nanoclusters with yellow fluorescent emission for $\mathrm{Cu}^{2+}$ sensing. Biosens. Bioelectron. 2015, 65, 397-403. [CrossRef] [PubMed]

49. Wu, J.; Jiang, K.; Wang, X.; Wang, C.; Zhang, C. On-off-on gold nanocluster-based near infrared fluorescent probe for recognition of $\mathrm{Cu}(\mathrm{II})$ and vitamin C. Microchim. Acta 2017, 184, 1315-1324. [CrossRef]

50. Liu, P.; Shang, L.; Li, H.; Cui, Y.; Qin, Y.; Wu, Y.; Hiltunen, J.K.; Chen, Z.; Shen, J. Synthesis of fluorescent $\alpha$-chymotrypsin A-functionalized gold nanoclusters and their application to blot-based technology for $\mathrm{Hg}^{2+}$ detection. RSC Adv. 2014, 4, 31536-31543. [CrossRef] 
51. Senthamizhan, A.; Celebioglu, A.; Uyar, T. Real-time selective visual monitoring of $\mathrm{Hg}^{2+}$ detection at ppt level: An approach to lighting electrospun nanofibers using gold nanoclusters. Sci. Rep. 2015, 5, 10403. [CrossRef] [PubMed]

52. Li, X.-J.; Ling, J.; Han, C.-L.; Chen, L.-Q.; Cao, Q.-E.; Ding, Z.-T. Chicken Egg White-stabilized Au Nanoclusters for Selective and Sensitive Detection of Hg(II). Anal. Sci. 2017, 33, 671-675. [CrossRef] [PubMed]

53. Chen, S.; Kuang, Y.; Zhang, P.; Huang, Y.; Wen, A.; Zeng, X.; Feng, R.; Nie, H.; Jiang, X.; Long, Y. A dual-functional spectroscopic probe for simultaneous monitoring $\mathrm{Cu}^{2+}$ and $\mathrm{Hg}^{2+}$ ions by two different sensing nature based on novel fluorescent gold nanoclusters. Sens. Actuators B 2017, 253, 283-291. [CrossRef]

54. Yang, L.; Chen, J.; Huang, T.; Huang, L.; Sun, Z.; Jiang, Y.; Yao, T.; Wei, S. Red-emitting Au7 nanoclusters with fluorescence sensitivity to $\mathrm{Fe}^{2+}$ ions. J. Mater. Chem. C 2017, 5, 4448-4454. [CrossRef]

55. Sun, J.; Zhang, J.; Jin, Y. 11-Mercaptoundecanoic acid directed one-pot synthesis of water-soluble fluorescent gold nanoclusters and their use as probes for sensitive and selective detection of $\mathrm{Cr}^{3+}$ and $\mathrm{Cr}^{6+}$. J. Mater. Chem. C 2013, 1, 138-143. [CrossRef]

56. Baral, A.; Basu, K.; Roy, S.; Banerjee, A. Blue Emitting Gold Cluster formation from Gold Nanorods: Selective and Sensitive Detection of Iron(III) ions in Aqueous Medium. ACS Sustain. Chem. Eng. 2017, 5, 1628-1637. [CrossRef]

57. Li, H.-W.; Yue, Y.; Liu, T.-Y.; Li, D.; Wu, Y. Fluorescence-Enhanced Sensing Mechanism of BSA-Protected Small Gold-Nanoclusters to Silver(I) Ions in Aqueous Solutions. J. Phys. Chem. C 2013, 117, 16159-16165. [CrossRef]

58. Liu, Y.; Ai, K.; Cheng, X.; Huo, L.; Lu, L. Gold-Nanocluster-Based Fluorescent Sensors for Highly Sensitive and Selective Detection of Cyanide in Water. Adv. Funct. Mater. 2010, 20, 951-956. [CrossRef]

59. Zhang, G.; Qiao, Y.; Xu, T.; Zhang, C.; Zhang, Y.; Shi, L.; Shuang, S.; Dong, C. Highly selective and sensitive nanoprobes for cyanide based on gold nanoclusters with red fluorescence emission. Nanoscale 2015, 7, 12666-12672. [CrossRef] [PubMed]

60. Shojaeifard, Z.; Hemmateenejad, B.; Shamsipur, M. Efficient On-Off Ratiometric Fluorescence Probe for Cyanide Ion Based on Perturbation of the Interaction between Gold Nanoclusters and a Copper(II)-Phthalocyanine Complex. ACS Appl. Mater. Interfaces 2016, 8, 15177-15186. [CrossRef] [PubMed]

61. Gopu, C.L.; Shanti Krishna, A.; Sreenivasan, K. Fluorimetric detection of hypochlorite using albumin stabilized gold nanoclusters. Sens. Actuators B 2015, 209, 798-802. [CrossRef]

62. Cui, M.-L.; Liu, J.-M.; Wang, X.-X.; Lin, L.-P.; Jiao, L.; Zheng, Z.-Y.; Zhang, L.-H.; Jiang, S.-L. A promising gold nanocluster fluorescent sensor for the highly sensitive and selective detection of $\mathrm{S}^{2-}$. Sens. Actuators $B$ 2013, 188, 53-58. [CrossRef]

63. Liu, H.; Yang, G.; Abdel-Halim, E.S.; Zhu, J.-J. Highly selective and ultrasensitive detection of nitrite based on fluorescent gold nanoclusters. Talanta 2013, 104, 135-139. [CrossRef] [PubMed]

64. Liu, J.-M.; Cui, M.-L.; Jiang, S.-L.; Wang, X.-X.; Lin, L.-P.; Jiao, L.; Zhang, L.-H.; Zheng, Z.-Y. BSA-protected gold nanoclusters as fluorescent sensor for selective and sensitive detection of pyrophosphate. Anal. Methods 2013, 5, 3942-3947. [CrossRef]

65. Sun, J.; Yang, F.; Yang, X. Synthesis of functionalized fluorescent gold nanoclusters for acid phosphatase sensing. Nanoscale 2015, 7, 16372-16380. [CrossRef] [PubMed]

66. Zhang, Y.; Li, M.; Niu, Q.; Gao, P.; Zhang, G.; Dong, C.; Shuang, S. Gold nanoclusters as fluorescent sensors for selective and sensitive hydrogen sulfide detection. Talanta 2017, 171, 143-151. [CrossRef] [PubMed]

67. Chen, X.; Baker, G.A. Cholesterol determination using protein-templated fluorescent gold nanocluster probes. Analyst 2013, 138, 7299-7302. [CrossRef] [PubMed]

68. Govindaraju, S.; Ankireddy, S.R.; Viswanath, B.; Kim, J.; Yun, K. Fluorescent Gold Nanoclusters for Selective Detection of Dopamine in Cerebrospinal fluid. Sci. Rep. 2017, 7, 40298. [CrossRef] [PubMed]

69. Wen, F.; Dong, Y.; Feng, L.; Wang, S.; Zhang, S.; Zhang, X. Horseradish Peroxidase Functionalized Fluorescent Gold Nanoclusters for Hydrogen Peroxide Sensing. Anal. Chem. 2011, 83, 1193-1196. [CrossRef] [PubMed]

70. He, Y.; Wang, X.; Zhu, J.; Zhong, S.; Song, G. Ni ${ }^{2+}$-modified gold nanoclusters for fluorescence turn-on detection of histidine in biological fluids. Analyst 2012, 137, 4005-4009. [CrossRef] [PubMed] 
71. Dai, H.; Shi, Y.; Wang, Y.; Sun, Y.; Hu, J.; Ni, P.; Li, Z. Label-free turn-on fluorescent detection of melamine based on the anti-quenching ability of $\mathrm{Hg}^{2+}$ to gold nanoclusters. Biosens. Bioelectron. 2014, 53, 76-81. [CrossRef] [PubMed]

72. Song, W.; Liang, R.-P.; Wang, Y.; Zhang, L.; Qiu, J.-D. Green synthesis of peptide-templated gold nanoclusters as novel fluorescence probes for detecting protein kinase activity. Chem. Commun. 2015, 51, 10006-10009. [CrossRef] [PubMed]

73. Chen, Z.; Qian, S.; Chen, J.; Chen, X. Highly fluorescent gold nanoclusters based sensor for the detection of quercetin. J. Nanopart. Res. 2012, 14, 1264. [CrossRef]

74. Li, S.; Huang, P.; Wu, F. Highly selective and sensitive detection of heparin based on competition-modulated assembly and disassembly of fluorescent gold nanoclusters. New J. Chem. 2017, 41, 717-723. [CrossRef]

75. Shang, L.; Nienhaus, G.U. Gold nanoclusters as novel optical probes for in vitro and in vivo fluorescence imaging. Biophys. Rev. 2012, 4, 313-322. [CrossRef] [PubMed]

76. Venkatesh, V.; Shukla, A.; Sivakumar, S.; Verma, S. Purine-Stabilized Green Fluorescent Gold Nanoclusters for Cell Nuclei Imaging Applications. ACS Appl. Mater. Interfaces 2014, 6, 2185-2191. [CrossRef] [PubMed]

77. Wang, Y.; Chen, J.-T.; Yan, X.-P. Fabrication of Transferrin Functionalized Gold Nanoclusters/Graphene Oxide Nanocomposite for Turn-On Near-Infrared Fluorescent Bioimaging of Cancer Cells and Small Animals. Anal. Chem. 2013, 85, 2529-2535. [CrossRef] [PubMed]

78. Barman, A.K.; Chaturbedi, A.; Subramaniam, K.; Verma, S. Imaging C. elegans with thiolated tryptophan-based NIR fluorescent gold nanoclusters. J. Nanopart. Res. 2013, 15, 2083. [CrossRef]

79. Zhou, W.; Cao, Y.; Sui, D.; Guan, W.; Lu, C.; Xie, J. Ultrastable BSA-capped gold nanoclusters with a polymer-like shielding layer against reactive oxygen species in living cells. Nanoscale 2016, 8, 9614-9620. [CrossRef] [PubMed]

80. Biswas, A.; Banerjee, S.; Gart, E.V.; Nagaraja, A.T.; McShane, M.J. Gold Nanocluster Containing Polymeric Microcapsules for Intracellular Ratiometric Fluorescence Biosensing. ACS Omega 2017, 2, 2499-2506. [CrossRef]

81. Han, Y.; Ding, C.; Zhou, J.; Tian, Y. Single Probe for Imaging and Biosensing of $\mathrm{pH}, \mathrm{Cu}^{2+}$ Ions, and $\mathrm{pH} / \mathrm{Cu}^{2+}$ in Live Cells with Ratiometric Fluorescence Signals. Anal. Chem. 2015, 87, 5333-5339. [CrossRef] [PubMed]

82. Deng, H.-H.; Wu, G.-W.; Zou, Z.-Q.; Peng, H.-P.; Liu, A.-L.; Lin, X.-H.; Xia, X.-H.; Chen, W. pH-Sensitive gold nanoclusters: Preparation and analytical applications for urea, urease, and urease inhibitor detection. Chem. Commun. 2015, 51, 7847-7850. [CrossRef] [PubMed]

83. Wu, Y.-T.; Shanmugam, C.; Tseng, W.-B.; Hiseh, M.-M.; Tseng, W.-L. A gold nanocluster-based fluorescent probe for simultaneous $\mathrm{pH}$ and temperature sensing and its application to cellular imaging and logic gates. Nanoscale 2016, 8, 11210-11216. [CrossRef] [PubMed]

84. Ali, R.; Saleh, S.M.; Aly, S.M. Fluorescent gold nanoclusters as $\mathrm{pH}$ sensors for the $\mathrm{pH} 5$ to 9 range and for imaging of blood cell pH values. Microchim. Acta 2017, 184, 3309-3315. [CrossRef]

85. Ghosh, S.; Anand, U.; Mukherjee, S. Luminescent Silver Nanoclusters Acting as a Label-Free Photoswitch in Metal Ion Sensing. Anal. Chem. 2014, 86, 3188-3194. [CrossRef] [PubMed]

86. Shang, L.; Dong, S. Silver nanocluster-based fluorescent sensors for sensitive detection of $\mathrm{Cu}(\mathrm{ii})$. J. Mater. Chem. 2008, 18, 4636-4640. [CrossRef]

87. Yuan, Z.; Cai, N.; Du, Y.; He, Y.; Yeung, E.S. Sensitive and Selective Detection of Copper Ions with Highly Stable Polyethyleneimine-Protected Silver Nanoclusters. Anal. Chem. 2014, 86, 419-426. [CrossRef] [PubMed]

88. Ma, F.; Liang, S.; Peng, Y.; Kuang, Y.; Zhang, X.; Chen, S.; Long, Y.; Zeng, R. Copper ion detection using novel silver nanoclusters stabilized with amido black 10B. Anal. Bioanal. Chem. 2016, 408, 3239-3246. [CrossRef] [PubMed]

89. Sun, Z.; Li, S.; Jiang, Y.; Qiao, Y.; Zhang, L.; Xu, L.; Liu, J.; Qi, W.; Wang, H. Silver Nanoclusters with Specific Ion Recognition Modulated by Ligand Passivation toward Fluorimetric and Colorimetric Copper Analysis and Biological Imaging. Sci. Rep. 2016, 6, 20553. [CrossRef] [PubMed]

90. Adhikari, B.; Banerjee, A. Facile Synthesis of Water-Soluble Fluorescent Silver Nanoclusters and HgII Sensing. Chem. Mater. 2010, 22, 4364-4371. [CrossRef]

91. MacLean, J.L.; Morishita, K.; Liu, J. DNA stabilized silver nanoclusters for ratiometric and visual detection of $\mathrm{Hg}^{2+}$ and its immobilization in hydrogels. Biosens. Bioelectron. 2013, 48, 82-86. [CrossRef] [PubMed]

92. Yin, J.; He, X.; Jia, X.; Wang, K.; Xu, F. Highly sensitive label-free fluorescent detection of $\mathrm{Hg}^{2+}$ ions by DNA molecular machine-based Ag nanoclusters. Analyst 2013, 138, 2350-2356. [CrossRef] [PubMed] 
93. Lee, J.; Park, J.; Hee Lee, H.; Park, H.; Kim, H.I.; Kim, W.J. Fluorescence switch for silver ion detection utilizing dimerization of DNA-Ag nanoclusters. Biosens. Bioelectron. 2015, 68, 642-647. [CrossRef] [PubMed]

94. Xu, N.; Zhu, Q.; Kong, X.-Y.; Meng, L. A sensitive detection of $\mathrm{Cr}(\mathrm{vi})$ in wide $\mathrm{pH}$ range using polyethyleneimine protected silver nanoclusters. Anal. Methods 2016, 8, 5684-5689. [CrossRef]

95. Chen, Z.; Lu, D.; Zhang, G.; Yang, J.; Dong, C.; Shuang, S. Glutathione capped silver nanoclusters-based fluorescent probe for highly sensitive detection of $\mathrm{Fe}^{3+}$. Sens. Actuators B 2014, 202, 631-637. [CrossRef]

96. Wang, C.; Wu, J.; Jiang, K.; Humphrey, M.G.; Zhang, C. Stable Ag nanoclusters-based nano-sensors: Rapid sonochemical synthesis and detecting $\mathrm{Pb}^{2+}$ in living cells. Sens. Actuators B 2017, 238, 1136-1143. [CrossRef]

97. Liu, X.; Wang, L.; Zhang, N.; Shangguan, D. Ratiometric fluorescent silver nanoclusters for the determination of mercury and copper ions. Anal. Methods 2015, 7, 8019-8024. [CrossRef]

98. Zhou, T.; Rong, M.; Cai, Z.; Yang, C.J.; Chen, X. Sonochemical synthesis of highly fluorescent glutathione-stabilized Ag nanoclusters and $\mathrm{S}^{2-}$ sensing. Nanoscale 2012, 4, 4103-4106. [CrossRef] [PubMed]

99. Gao, Z.; Liu, F.; Hu, R.; Zhao, M.; Shao, N. Lysozyme-stabilized Ag nanoclusters: Synthesis of different compositions and fluorescent responses to sulfide ions with distinct modes. RSC Adv. 2016, 6, 66233-66241. [CrossRef]

100. Huang, X.; Shahzad, S.A.; Li, Y.; Zhang, Y.; Sang, L.; Zhou, H.; Jiang, H.; Kam-Wing Lo, K.; Yu, C. Silver nanoclusters capped silica nanoparticles as a ratiometric photoluminescence nanosensor for the selective detection of $\mathrm{I}^{-}$and $\mathrm{S}^{2-}$. Anal. Chim. Acta 2017, 988, 74-80. [CrossRef] [PubMed]

101. Chen, C.; Yuan, Z.; Chang, H.-T.; Lu, F.; Li, Z.; Lu, C. Silver nanoclusters as fluorescent nanosensors for selective and sensitive nitrite detection. Anal. Methods 2016, 8, 2628-2633. [CrossRef]

102. Feng, L.; Sun, Z.; Liu, H.; Liu, M.; Jiang, Y.; Fan, C.; Cai, Y.; Zhang, S.; Xu, J.; Wang, H. Silver nanoclusters with enhanced fluorescence and specific ion recognition capability triggered by alcohol solvents: A highly selective fluorimetric strategy for detecting iodide ions in urine. Chem. Commun. 2017, 53, 9466-9469. [CrossRef] [PubMed]

103. Fu, L.; Li, C.; Li, Y.; Chen, S.; Long, Y.; Zeng, R. Simultaneous determination of iodide and bromide using a novel LSPR fluorescent Ag nanocluster probe. Sens. Actuators B 2017, 240, 315-321. [CrossRef]

104. Liu, F.; Bing, T.; Shangguan, D.; Zhao, M.; Shao, N. Ratiometric Fluorescent Biosensing of Hydrogen Peroxide and Hydroxyl Radical in Living Cells with Lysozyme-Silver Nanoclusters: Lysozyme as Stabilizing Ligand and Fluorescence Signal Unit. Anal. Chem. 2016, 88, 10631-10638. [CrossRef] [PubMed]

105. Liu, T.; Su, Y.; Song, H.; Lv, Y. Microwave-assisted green synthesis of ultrasmall fluorescent water-soluble silver nanoclusters and its application in chiral recognition of amino acids. Analyst 2013, 138, 6558-6564. [CrossRef] [PubMed]

106. Huang, Z.; Pu, F.; Lin, Y.; Ren, J.; Qu, X. Modulating DNA-templated silver nanoclusters for fluorescence turn-on detection of thiol compounds. Chem. Commun. 2011, 47, 3487-3489. [CrossRef] [PubMed]

107. Zhang, N.; Qu, F.; Luo, H.Q.; Li, N.B. Sensitive and selective detection of biothiols based on target-induced agglomeration of silvernanoclusters. Biosens. Bioelectron. 2013, 42, 214-218. [CrossRef] [PubMed]

108. Yuan, X.; Tay, Y.; Dou, X.; Luo, Z.; Leong, D.T.; Xie, J. Glutathione-Protected Silver Nanoclusters as Cysteine-Selective Fluorometric and Colorimetric Probe. Anal. Chem. 2013, 85, 1913-1919. [CrossRef] [PubMed]

109. Zhu, J.; Song, X.; Gao, L.; Li, Z.; Liu, Z.; Ding, S.; Zou, S.; He, Y. A highly selective sensor of cysteine with tunable sensitivity and detection window based on dual-emission Ag nanoclusters. Biosens. Bioelectron. 2014, 53, 71-75. [CrossRef] [PubMed]

110. Dong, J.X.; Gao, Z.F.; Zhang, Y.; Li, B.L.; Zhang, W.; Lei, J.L.; Li, N.B.; Luo, H.Q. The pH-switchable agglomeration and dispersion behavior of fluorescent Ag nanoclusters and its applications in urea and glucose biosensing. NPG Asia Mater. 2016, 8, e335. [CrossRef]

111. Ren, H.; Li, M.; Fu, Y.; Jin, L. Silver nanoclusters functionalized by chromotropic acid and layered double hydroxides for the turn-on detection of melamine. J. Mater. Chem. C 2016, 4, 6104-6109. [CrossRef]

112. Chen, Y.; Sun, Y.; Song, R.; Song, S.; Zhao, Y.; Yang, X.; Yu, C.; Lin, Q. Fluorometric “Turn-On” glucose sensing through the in situ generation of silver nanoclusters. RSC Adv. 2017, 7, 1396-1400. [CrossRef]

113. Mao, B.; Qu, F.; Zhu, S.; You, J. Fluorescence turn-on strategy based on silver nanoclusters-Cu ${ }^{2+}$ system for trace detection of quinolones. Sens. Actuators B 2016, 234, 338-344. [CrossRef] 
114. Sharma, J.; Yeh, H.-C.; Yoo, H.; Werner, J.H.; Martinez, J.S. Silver nanocluster aptamers: In situ generation of intrinsically fluorescent recognition ligands for protein detection. Chem. Commun. 2011, 47, 2294-2296. [CrossRef] [PubMed]

115. Zhou, Y.W.; Li, C.M.; Liu, Y.; Huang, C.Z. Effective detection and cell imaging of prion protein with new prepared targetable yellow-emission silver nanoclusters. Analyst 2013, 138, 873-878. [CrossRef] [PubMed]

116. Chang, Y.; Zhang, P.; Yu, Y.; Du, Y.Q.; Wang, W.; Huang, C.Z. DNA-templated silver nanoclusters as label-free fluorescent probes for detection of bleomycin. Anal. Methods 2013, 5, 6200-6204. [CrossRef]

117. Basiruddin, S.K.; Chakraborty, A. One step synthesis of maltose functionalized red fluorescent Ag cluster for specific glycoprotein detection and cellular imaging probe. RSC Adv. 2014, 4, 43098-43104. [CrossRef]

118. Yang, S.W.; Vosch, T. Rapid Detection of MicroRNA by a Silver Nanocluster DNA Probe. Anal. Chem. 2011, 83, 6935-6939. [CrossRef] [PubMed]

119. Liu, Y.-Q.; Zhang, M.; Yin, B.-C.; Ye, B.-C. Attomolar Ultrasensitive MicroRNA Detection by DNA-Scaffolded Silver-Nanocluster Probe Based on Isothermal Amplification. Anal. Chem. 2012, 84, 5165-5169. [CrossRef] [PubMed]

120. Wang, G.; Zhu, Y.; Chen, L.; Wang, L.; Zhang, X. Target-induced quenching for highly sensitive detection of nucleic acids based on label-free luminescent supersandwich DNA/silver nanoclusters. Analyst 2014, 139, 165-169. [CrossRef] [PubMed]

121. Zhang, Y.; Zhu, C.; Zhang, L.; Tan, C.; Yang, J.; Chen, B.; Wang, L.; Zhang, H. DNA-Templated Silver Nanoclusters for Multiplexed Fluorescent DNA Detection. Small 2015, 11, 1385-1389. [CrossRef] [PubMed]

122. Zhu, J.; Zhang, L.; Teng, Y.; Lou, B.; Jia, X.; Gu, X.; Wang, E. G-quadruplex enhanced fluorescence of DNA-silver nanoclusters and their application in bioimaging. Nanoscale 2015, 7, 13224-13229. [CrossRef] [PubMed]

123. Le Guével, X.; Spies, C.; Daum, N.; Jung, G.; Schneider, M. Highly fluorescent silver nanoclusters stabilized by glutathione: A promising fluorescent label for bioimaging. Nano Res. 2012, 5, 379-387. [CrossRef]

124. Qu, F.; Li, N.B.; Luo, H.Q. Highly Sensitive Fluorescent and Colorimetric pH Sensor Based on Polyethylenimine-Capped Silver Nanoclusters. Langmuir 2013, 29, 1199-1205. [CrossRef] [PubMed]

125. Mao, M.; Deng, C.; He, Y.; Ge, Y.; Song, G. Fluorescence Detection of p-Nitrophenol in Water Using Bovine Serum Albumin Capped ag Nanoclusters. J. Fluoresc. 2017, 27, 1421-1426. [CrossRef] [PubMed]

126. Enkin, N.; Sharon, E.; Golub, E.; Willner, I. Ag Nanocluster/DNA Hybrids: Functional Modules for the Detection of Nitroaromatic and RDX Explosives. Nano Lett. 2014, 14, 4918-4922. [CrossRef] [PubMed]

127. Cao, H.; Chen, Z.; Zheng, H.; Huang, Y. Copper nanoclusters as a highly sensitive and selective fluorescence sensor for ferric ions in serum and living cells by imaging. Biosens. Bioelectron. 2014, 62, 189-195. [CrossRef] [PubMed]

128. Das, N.K.; Ghosh, S.; Priya, A.; Datta, S.; Mukherjee, S. Luminescent Copper Nanoclusters as a Specific Cell-Imaging Probe and a Selective Metal Ion Sensor. J. Phys. Chem. C 2015, 119, 24657-24664. [CrossRef]

129. Liu, Z.-C.; Qi, J.-W.; Hu, C.; Zhang, L.; Song, W.; Liang, R.-P.; Qiu, J.-D. Cu nanoclusters-based ratiometric fluorescence probe for ratiometric and visualization detection of copper ions. Anal. Chimica Acta 2015, 895, 95-103. [CrossRef] [PubMed]

130. Hu, X.; Wang, W.; Huang, Y. Copper nanocluster-based fluorescent probe for sensitive and selective detection of $\mathrm{Hg}^{2+}$ in water and food stuff. Talanta 2016, 154, 409-415. [CrossRef] [PubMed]

131. Wang, C.; Cheng, H.; Huang, Y.; Xu, Z.; Lin, H.; Zhang, C. Facile sonochemical synthesis of pH-responsive copper nanoclusters for selective and sensitive detection of $\mathrm{Pb}^{2+}$ in living cells. Analyst 2015, 140, 5634-5639. [CrossRef] [PubMed]

132. Han, B.-Y.; Hou, X.-F.; Xiang, R.-C.; Yu, M.-B.; Li, Y.; Peng, T.-T.; He, G.-H. Detection of Lead Ion Based on Aggregation-induced Emission of Copper Nanoclusters. Chin. J. Anal. Chem. 2017, 45, 23-27. [CrossRef]

133. Goswami, N.; Giri, A.; Bootharaju, M.S.; Xavier, P.L.; Pradeep, T.; Pal, S.K. Copper Quantum Clusters in Protein Matrix: Potential Sensor of $\mathrm{Pb}^{2+}$ Ion. Anal. Chem. 2011, 83, 9676-9680. [CrossRef] [PubMed]

134. Hu, X.; Mao, X.; Zhang, X.; Huang, Y. One-step synthesis of orange fluorescent copper nanoclusters for sensitive and selective sensing of $\mathrm{Al}^{3+}$ ions in food samples. Sens. Actuators B 2017, 247, 312-318. [CrossRef]

135. Lin, L.; Hu, Y.; Zhang, L.; Huang, Y.; Zhao, S. Photoluminescence light-up detection of zinc ion and imaging in living cells based on the aggregation induced emission enhancement of glutathione-capped copper nanoclusters. Biosens. Bioelectron. 2017, 94, 523-529. [CrossRef] [PubMed] 
136. Li, Z.; Guo, S.; Lu, C. A highly selective fluorescent probe for sulfide ions based on aggregation of $\mathrm{Cu}$ nanocluster induced emission enhancement. Analyst 2015, 140, 2719-2725. [CrossRef] [PubMed]

137. Khonkayan, K.; Sansuk, S.; Srijaranai, S.; Tuntulani, T.; Saiyasombat, C.; Busayaporn, W.; Ngeontae, W. New approach for detection of chromate ion by preconcentration with mixed metal hydroxide coupled with fluorescence sensing of copper nanoclusters. Microchim. Acta 2017, 184, 2965-2974. [CrossRef]

138. Zhong, Y.; Wang, Q.; He, Y.; Ge, Y.; Song, G. A novel fluorescence and naked eye sensor for iodide in urine based on the iodide induced oxidative etching and aggregation of $\mathrm{Cu}$ nanoclusters. Sens. Actuators B 2015, 209, 147-153. [CrossRef]

139. Zheng, X.-J.; Liang, R.-P.; Li, Z.-J.; Zhang, L.; Qiu, J.-D. One-step, stabilizer-free and green synthesis of Cu nanoclusters as fluorescent probes for sensitive and selective detection of nitrite ions. Sens. Actuators B 2016, 230, 314-319. [CrossRef]

140. Zhou, D.-L.; Huang, H.; Wang, Y. Sensitive and selective detection of nitrite ions with highly fluorescent glutathione-stabilized copper nanoclusters. Anal. Methods 2017, 9, 5668-5673. [CrossRef]

141. Cang, J.; Wang, C.-W.; Chen, P.-C.; Lin, Y.-J.; Li, Y.-C.; Chang, H.-T. Control of pH for separated quantitation of nitrite and cyanide ions using photoluminescent copper nanoclusters. Anal. Methods 2017, 9, 5254-5259. [CrossRef]

142. Wang, W.; Zhan, L.; Du, Y.Q.; Leng, F.; Huang, C.Z. A new spectrofluorometric method for pyrophosphate assay based on the fluorescence enhancement of trypsin-stabilized copper clusters. Anal. Methods 2015, 7, 638-642. [CrossRef]

143. Hu, Y.; Wu, Y.; Chen, T.; Chu, X.; Yu, R. Double-strand DNA-templated synthesis of copper nanoclusters as novel fluorescence probe for label-free detection of biothiols. Anal. Methods 2013, 5, 3577-3581. [CrossRef]

144. Hu, L.; Yuan, Y.; Zhang, L.; Zhao, J.; Majeed, S.; Xu, G. Copper nanoclusters as peroxidase mimetics and their applications to $\mathrm{H}_{2} \mathrm{O}_{2}$ and glucose detection. Anal. Chim. Acta 2013, 762, 83-86. [CrossRef] [PubMed]

145. Zhao, X.J.; Huang, C.Z. Water-soluble luminescent copper nanoclusters reduced and protected by histidine for sensing of guanosine 5'-triphosphate. New J. Chem. 2014, 38, 3673-3677. [CrossRef]

146. Wang, Y.-M.; Liu, J.-W.; Duan, L.-Y.; Liu, S.-J.; Jiang, J.-H. Aptamer-based fluorometric determination of ATP by using target-cycling strand displacement amplification and copper nanoclusters. Microchim. Acta 2017, 184, 4183-4188. [CrossRef]

147. Wang, C.; Shu, S.; Yao, Y.; Song, Q. A fluorescent biosensor of lysozyme-stabilized copper nanoclusters for the selective detection of glucose. RSC Adv. 2015, 5, 101599-101606. [CrossRef]

148. Borghei, Y.-S.; Hosseini, M.; Khoobi, M.; Ganjali, M.R. Novel Fluorometric Assay for Detection of Cysteine as a Reducing Agent and Template in Formation of Copper Nanoclusters. J. Fluoresc. 2017, 27, 529-536. [CrossRef] [PubMed]

149. Li, X.-G.; Zhang, F.; Gao, Y.; Zhou, Q.-M.; Zhao, Y.; Li, Y.; Huo, J.-Z.; Zhao, X.-J. Facile synthesis of red emitting 3-aminophenylboronic acid functionalized copper nanoclusters for rapid, selective and highly sensitive detection of glycoproteins. Biosens. Bioelectron. 2016, 86, 270-276. [CrossRef] [PubMed]

150. Zhao, M.; Qian, Z.; Zhong, M.; Chen, Z.; Ao, H.; Feng, H. Fabrication of Stable and Luminescent Copper Nanocluster-Based AIE Particles and Their Application in $\beta$-Galactosidase Activity Assay. ACS Appl. Mater. Interfaces 2017, 9, 32887-32895. [CrossRef] [PubMed]

151. Wang, X.-P.; Yin, B.-C.; Ye, B.-C. A novel fluorescence probe of dsDNA-templated copper nanoclusters for quantitative detection of microRNAs. RSC Adv. 2013, 3, 8633-8636. [CrossRef]

152. Borghei, Y.-S.; Hosseini, M.; Ganjali, M.R. Fluorescence based turn-on strategy for determination of microRNA-155 using DNA-templated copper nanoclusters. Microchim. Acta 2017, 184, 2671-2677. [CrossRef]

153. Huang, H.; Li, H.; Wang, A.-J.; Zhong, S.-X.; Fang, K.-M.; Feng, J.-J. Green synthesis of peptide-templated fluorescent copper nanoclusters for temperature sensing and cellular imaging. Analyst 2014, 139, 6536-6541. [CrossRef] [PubMed]

154. Basu, K.; Gayen, K.; Mitra, T.; Baral, A.; Roy, S.S.; Banerjee, A. Different Color Emissive Copper Nanoclusters for Cancer Cell Imaging. ChemNanoMat 2017, 3, 808-814. [CrossRef]

155. Wang, W.; Leng, F.; Zhan, L.; Chang, Y.; Yang, X.X.; Lan, J.; Huang, C.Z. One-step prepared fluorescent copper nanoclusters for reversible $\mathrm{pH}$-sensing. Analyst 2014, 139, 2990-2993. [CrossRef] [PubMed]

156. Zhang, G.; Xu, T.; Du, H.; Qiao, Y.; Guo, X.; Shi, L.; Zhang, Y.; Shuang, S.; Dong, C.; Ma, H. A reversible fluorescent $\mathrm{pH}$-sensing system based on the one-pot synthesis of natural silk fibroin-capped copper nanoclusters. J. Mater. Chem. C 2016, 4, 3540-3545. [CrossRef] 
157. Deng, X.; Huang, X.; Wu, D. Förster resonance-energy-transfer detection of 2,4,6-trinitrophenol using copper nanoclusters. Anal. Bioanal. Chem. 2015, 407, 4607-4613. [CrossRef] [PubMed]

158. Wang, Z.; Chen, R.; Xiong, Y.; Cepe, K.; Schneider, J.; Zboril, R.; Lee, C.-S.; Rogach, A.L. Incorporating Copper Nanoclusters into Metal-Organic Frameworks: Confinement-Assisted Emission Enhancement and Application for Trinitrotoluene Detection. Part. Part. Syst. Charact. 2017, 34. [CrossRef]

159. Huang, Y.; Liu, W.; Feng, H.; Ye, Y.; Tang, C.; Ao, H.; Zhao, M.; Chen, G.; Chen, J.; Qian, Z. Luminescent Nanoswitch Based on Organic-Phase Copper Nanoclusters for Sensitive Detection of Trace Amount of Water in Organic Solvents. Anal. Chem. 2016, 88, 7429-7434. [CrossRef] [PubMed]

160. Su, X.; Liu, J. pH-Guided Self-Assembly of Copper Nanoclusters with Aggregation-Induced Emission. ACS Appl. Mater. Interfaces 2017, 9, 3902-3910. [CrossRef] [PubMed]

161. Duchesne, P.N.; Zhang, P. Local structure of fluorescent platinum nanoclusters. Nanoscale 2012, 4, 4199-4205. [CrossRef] [PubMed]

162. George, A.; Gopalakrishnan, H.; Mandal, S. Surfactant free platinum nanocluster as fluorescent probe for the selective detection of Fe (III) ions in aqueous medium. Sens. Actuators B 2017, 243, 332-337. [CrossRef]

163. Xia, X.; Zhang, Y.; Wang, J. Novel fabrication of highly fluorescent Pt nanoclusters and their applications in hypochlorite assay. RSC Adv. 2014, 4, 25365-25368. [CrossRef]

164. Jin, L.; Meng, Z.; Zhang, Y.; Cai, S.; Zhang, Z.; Li, C.; Shang, L.; Shen, Y. Ultrasmall Pt Nanoclusters as Robust Peroxidase Mimics for Colorimetric Detection of Glucose in Human Serum. ACS Appl. Mater. Interfaces 2017, 9, 10027-10033. [CrossRef] [PubMed]

165. Xu, N.; Li, H.-W.; Wu, Y. Hydrothermal synthesis of polyethylenimine-protected high luminescent Pt-nanoclusters and their application to the detection of nitroimidazoles. Anal. Chim. Acta 2017, 958, 51-58. [CrossRef] [PubMed]

166. Chen, D.; Gao, S.; Ge, W.; Li, Q.; Jiang, H.; Wang, X. One-step rapid synthesis of fluorescent platinum nanoclusters for cellular imaging and photothermal treatment. RSC Adv. 2014, 4, 40141-40145. [CrossRef]

167. Chen, D.; Zhao, C.; Ye, J.; Li, Q.; Liu, X.; Su, M.; Jiang, H.; Amatore, C.; Selke, M.; Wang, X. In Situ Biosynthesis of Fluorescent Platinum Nanoclusters: Toward Self-Bioimaging-Guided Cancer Theranostics. ACS Appl. Mater. Interfaces 2015, 7, 18163-18169. [CrossRef] [PubMed]

168. King, N.S.; Liu, L.; Yang, X.; Cerjan, B.; Everitt, H.O.; Nordlander, P.; Halas, N.J. Fano Resonant Aluminum Nanoclusters for Plasmonic Colorimetric Sensing. ACS Nano 2015, 9, 10628-10636. [CrossRef] [PubMed]

169. Atta, N.F.; El-Kady, M.F.; Galal, A. Palladium nanoclusters-coated polyfuran as a novel sensor for catecholamine neurotransmitters and paracetamol. Sens. Actuators B 2009, 141, 566-574. [CrossRef]

170. Sarparast, M.; Noori, A.; Ilkhani, H.; Bathaie, S.Z.; El-Kady, M.F.; Wang, L.J.; Pham, H.; Marsh, K.L.; Kaner, R.B.; Mousavi, M.F. Cadmium nanoclusters in a protein matrix: Synthesis, characterization, and application in targeted drug delivery and cellular imaging. Nano Res. 2016, 9, 3229-3246. [CrossRef]

171. Vankayala, R.; Gollavelli, G.; Mandal, B.K. Highly fluorescent and biocompatible iridium nanoclusters for cellular imaging. J. Mater. Sci. 2013, 24, 1993-2000. [CrossRef] [PubMed]

172. Su, Y.-T.; Lan, G.-Y.; Chen, W.-Y.; Chang, H.-T. Detection of Copper Ions Through Recovery of the Fluorescence of DNA-Templated Copper/Silver Nanoclusters in the Presence of Mercaptopropionic Acid. Anal. Chem. 2010, 82, 8566-8572. [CrossRef] [PubMed]

173. Zhou, T.-Y.; Lin, L.-P.; Rong, M.-C.; Jiang, Y.-Q.; Chen, X. Silver-Gold Alloy Nanoclusters as a Fluorescence-Enhanced Probe for Aluminum Ion Sensing. Anal. Chem. 2013, 85, 9839-9844. [CrossRef] [PubMed]

174. Zhang, N.; Si, Y.; Sun, Z.; Chen, L.; Li, R.; Qiao, Y.; Wang, H. Rapid, Selective, and Ultrasensitive Fluorimetric Analysis of Mercury and Copper Levels in Blood Using Bimetallic Gold-Silver Nanoclusters with "Silver Effect" —Enhanced Red Fluorescence. Anal. Chem. 2014, 86, 11714-11721. [CrossRef] [PubMed]

175. Zheng, B.; Zheng, J.; Yu, T.; Sang, A.; Du, J.; Guo, Y.; Xiao, D.; Choi, M.M.F. Fast microwave-assisted synthesis of AuAg bimetallic nanoclusters with strong yellow emission and their response to mercury(II) ions. Sens. Actuators B 2015, 221, 386-392. [CrossRef] 
176. Huang, H.; Li, H.; Feng, J.-J.; Wang, A.-J. One-step green synthesis of fluorescent bimetallic Au/Ag nanoclusters for temperature sensing and in vitro detection of $\mathrm{Fe}^{3+}$. Sens. Actuators, B 2016, 223, 550-556. [CrossRef]

177. Yang, Y.; Sun, Y.; Liao, S.; Wu, Z.; Yu, R. Bimetallic gold-silver nanocluster fluorescent probes for Cr(iii) and Cr(vi). Anal. Methods 2016, 8, 7237-7241. [CrossRef]

178. Zhang, T.; Xu, H.; Xu, S.; Dong, B.; Wu, Z.; Zhang, X.; Zhang, L.; Song, H. DNA stabilized Ag-Au alloy nanoclusters and their application as sensing probes for mercury ions. RSC Adv. 2016, 6, 51609-51618. [CrossRef]

179. Ding, S.-N.; Guo, Y.-X. One-pot synthesis of dual-emitting BSA-Pt-Au bimetallic nanoclusters for fluorescence ratiometric detection of mercury ions and cysteine. Anal. Methods 2015, 7, 5787-5793. [CrossRef]

180. Wang, Z.-X.; Guo, Y.-X.; Ding, S.-N. Fluorometric determination of cadmium(II) and mercury(II) using nanoclusters consisting of a gold-nickel alloy. Microchim. Acta 2015, 182, 2223-2231. [CrossRef]

181. Chen, W.-Y.; Lan, G.-Y.; Chang, H.-T. Use of Fluorescent DNA-Templated Gold/Silver Nanoclusters for the Detection of Sulfide Ions. Anal. Chem. 2011, 83, 9450-9455. [CrossRef] [PubMed]

182. Zhang, P.; Wang, Y.; Chen, L.; Yin, Y. Bimetallic nanoclusters with strong red fluorescence for sensitive detection of hypochlorite in tap water. Microchim. Acta 2017, 184, 3781-3787. [CrossRef]

183. Zhou, Q.; Lin, Y.; Xu, M.; Gao, Z.; Yang, H.; Tang, D. Facile Synthesis of Enhanced Fluorescent Gold-Silver Bimetallic Nanocluster and Its Application for Highly Sensitive Detection of Inorganic Pyrophosphatase Activity. Anal. Chem. 2016, 88, 8886-8892. [CrossRef] [PubMed]

184. Li, Z.; Liu, R.; Xing, G.; Wang, T.; Liu, S. A novel fluorometric and colorimetric sensor for iodide determination using DNA-templated gold/silver nanoclusters. Biosens. Bioelectron. 2017, 96, 44-48. [CrossRef] [PubMed]

185. Ding, Y.; Li, X.; Chen, C.; Ling, J.; Li, W.; Guo, Y.; Yan, J.; Zha, L.; Cai, J. A rapid evaluation of acute hydrogen sulfide poisoning in blood based on DNA-Cu/Ag nanocluster fluorescence probe. Sci. Rep. 2017, 7, 9638. [CrossRef] [PubMed]

186. Wang, Z.-X.; Ding, S.-N.; Jomma Narjh, E.Y. Determination of Thiols by Fluorescence using Au@Ag Nanoclusters as Probes. Anal. Lett. 2015, 48, 647-658. [CrossRef]

187. Sun, J.; Yang, F.; Zhao, D.; Chen, C.; Yang, X. Integrated Logic Gate for Fluorescence Turn-on Detection of Histidine and Cysteine Based on Ag/Au Bimetallic Nanoclusters-Cu ${ }^{2+}$ Ensemble. ACS Appl. Mater. Interfaces 2015, 7, 6860-6866. [CrossRef] [PubMed]

188. Feng, J.; Huang, P.; Wu, F.-Y. Gold-platinum bimetallic nanoclusters with enhanced peroxidase-like activity and their integrated agarose hydrogel-based sensing platform for the colorimetric analysis of glucose levels in serum. Analyst 2017, 142, 4106-4115. [CrossRef] [PubMed]

189. Ahn, J.K.; Kim, H.Y.; Baek, S.; Park, H.G. A new s-adenosylhomocysteine hydrolase-linked method for adenosine detection based on DNA-templated fluorescent $\mathrm{Cu} / \mathrm{Ag}$ nanoclusters. Biosens. Bioelectron. 2017, 93, 330-334. [CrossRef] [PubMed]

190. Li, W.; Li, W.; Hu, Y.; Xia, Y.; Shen, Q.; Nie, Z.; Huang, Y.; Yao, S. A fluorometric assay for acetylcholinesterase activity and inhibitor detection based on DNA-templated copper/silver nanoclusters. Biosens. Bioelectron. 2013, 47, 345-349. [CrossRef] [PubMed]

191. Hu, D.-H.; Sheng, Z.-H.; Zhang, P.-F.; Yang, D.-Z.; Liu, S.-H.; Gong, P.; Gao, D.-Y.; Fang, S.-T.; Ma, Y.-F.; Cai, L.-T. Hybrid gold-gadolinium nanoclusters for tumor-targeted NIRF/CT/MRI triple-modal imaging in vivo. Nanoscale 2013, 5, 1624-1628. [CrossRef] [PubMed]

192. Dutta, D.; Chattopadhyay, A.; Ghosh, S.S. Cationic BSA Templated Au-Ag Bimetallic Nanoclusters As a Theranostic Gene Delivery Vector for HeLa Cancer Cells. ACS Biomater. Sci. Eng. 2016, 2, 2090-2098. [CrossRef]

193. Chen, L.; Zhang, Y.; Jiang, H.; Wang, X.; Liu, C. Cytidine Mediated AuAg Nanoclusters as Bright Fluorescent Probe for Tumor Imaging in vivo. Chin. J. Chem. 2016, 34, 589-593. [CrossRef]

194. Chen, P.-C.; Ma, J.-Y.; Chen, L.-Y.; Lin, G.-L.; Shih, C.-C.; Lin, T.-Y.; Chang, H.-T. Photoluminescent AuCu bimetallic nanoclusters as pH sensors and catalysts. Nanoscale 2014, 6, 3503-3507. [CrossRef] [PubMed] 
195. Han, B.; Hou, X.; Xiang, R.; He, G. Synthesis of highly luminescent Cu/Ag bimetal nanoclusters and their application in a temperature sensor. Anal. Methods 2017, 9, 4028-4032. [CrossRef]

196. Goswami, N.; Yao, Q.; Luo, Z.; Li, J.; Chen, T.; Xie, J. Luminescent Metal Nanoclusters with Aggregation-Induced Emission. J. Phys. Chem. Lett. 2016, 7, 962-975. [CrossRef] [PubMed]

197. Kang, X.; Xiong, L.; Wang, S.; Yu, H.; Jin, S.; Song, Y.; Chen, T.; Zheng, L.; Pan, C.; Pei, Y.; et al. Shape-Controlled Synthesis of Trimetallic Nanoclusters: Structure Elucidation and Properties Investigation. Chem. Eur. J. 2016, 22, 17145-17150. [CrossRef] [PubMed] 